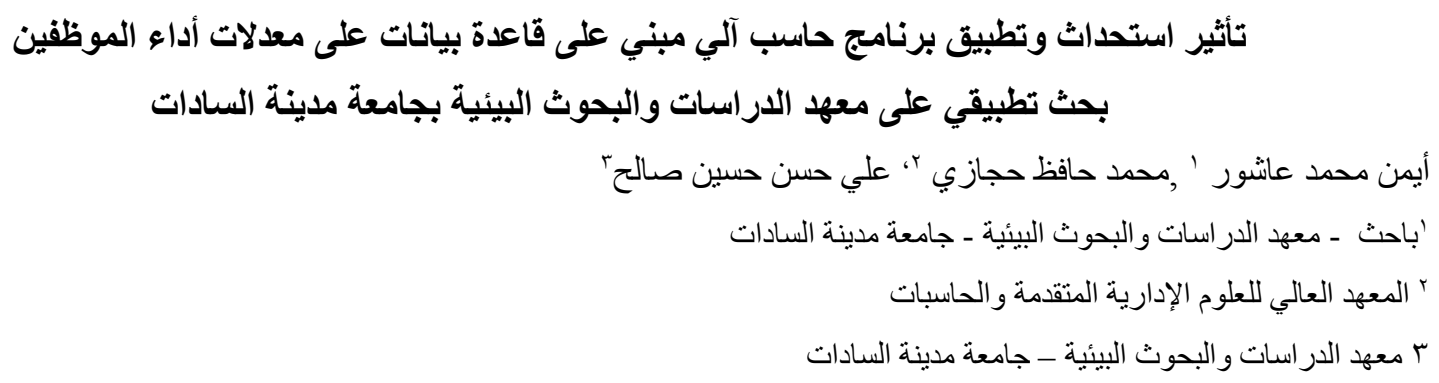

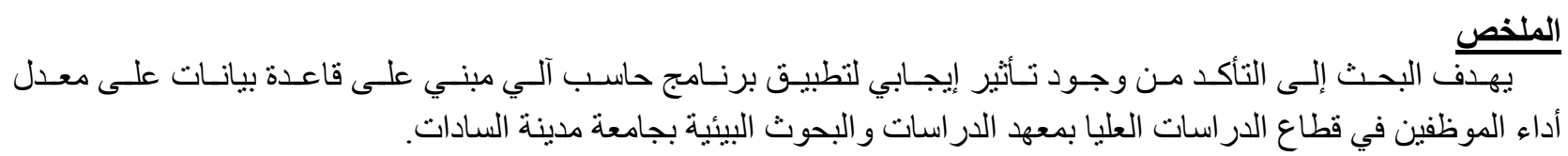

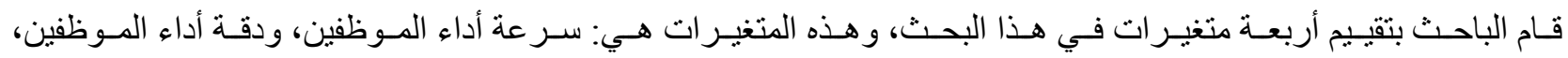
وتجنب ومنع أخطاء الموظفين، و إنشاء تقارير لتحسين عمل المبن الموظفين.

صـمم الباحـث اسـتياناً لقيـاس تـأثير البرنـامج على أداء المـوظفين واسـتخدم الأسـاليب الإحصــائية المناسـبة لتحليـل النتـائج

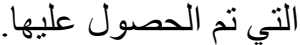
كلمات داله: قاعدة بيانات، برنامج حاسب آلي، معدلات الأداء، السرعة، الدقة، تجنب الأخطاء، توليد التقارير.

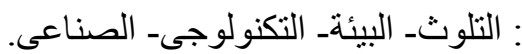

\title{
Abstract:
}

The research aims to confirm that there is a positive effect of applying a computer program based on a database to the performance rate of the employees of the graduate sector at Environmental Studies \& Research Institute, University of Sadat City.

The researcher evaluated four variables in that research, these variables are: the speed of employee's performance, the accuracy of employees' performance, avoids errors of employees, and generating reports to improve employees work.

The researcher designed a questionnaire to measure the effect of the program on the employees' performance and used appropriate statistical methods to analyze the results obtained. .

Key worde:Database, Computer program, Performance Rate, Speed, Accuracy, Errors, Generating Reports.

\section{مقدمه الاراسة}

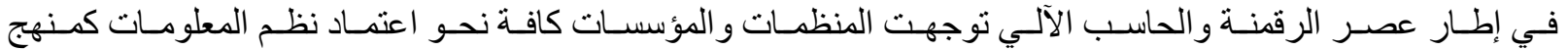

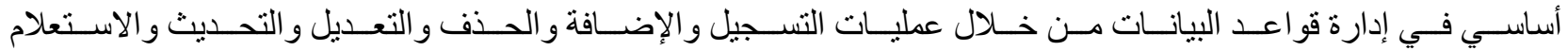

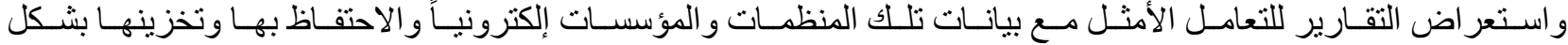

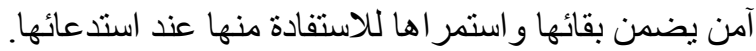

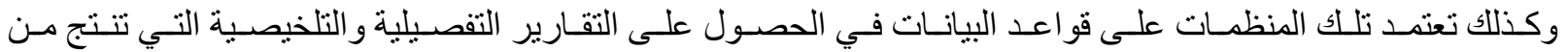
عمليات الاستعلامات التي تتنجها قو اعد البيانات وذلك من خلال واجهات التهات تعامل سهلة ومرنة يتفاعل معها المستخدم.

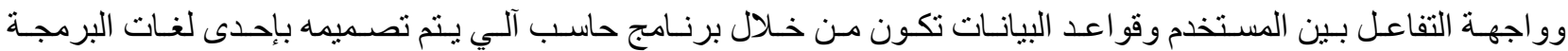
مع إنشاء اتصال بين البرنامج وقاعدة البيانات لكي تتم عملية تمرير البيانات بينهما. 


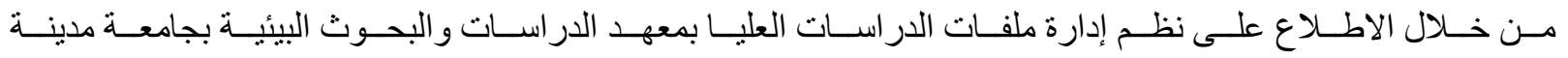

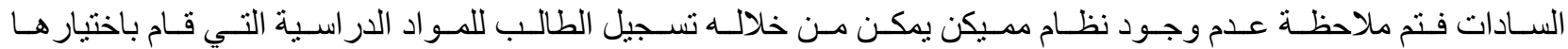

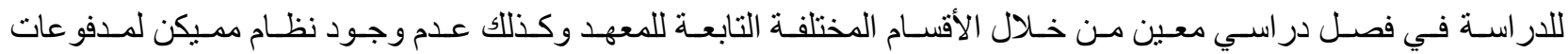
الطالب يمكن من خلاله متابعة الموقف المالي فرالي للطلاب.

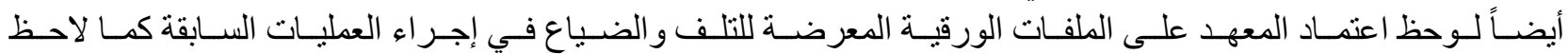

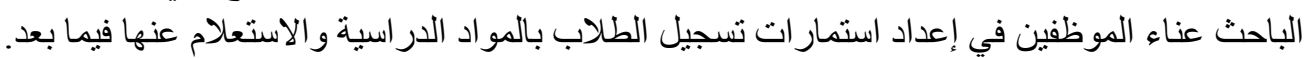

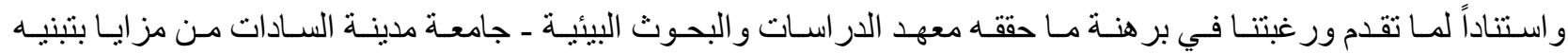

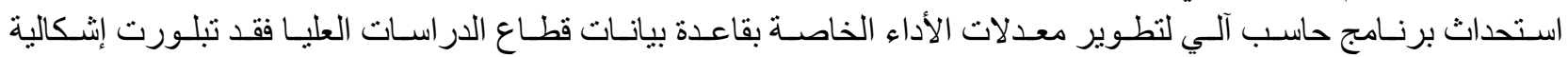

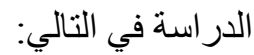

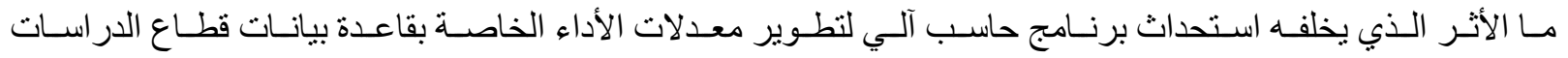

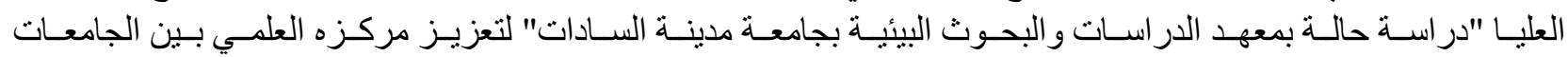

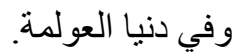
و عليه واتساقاً مع ما تقدم يمكن صياغة مشكلة البحث في السؤ ال الرئيسي التالي:

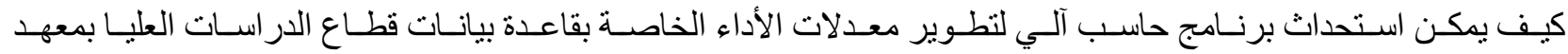

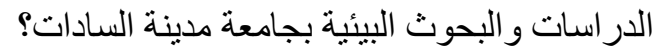

ومنه تتفرع الأسئلة الفرعية التالية:

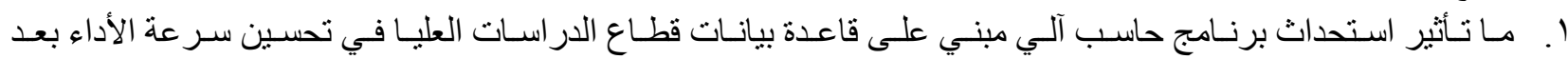

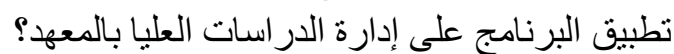

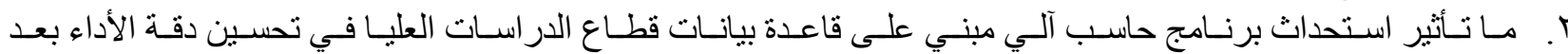

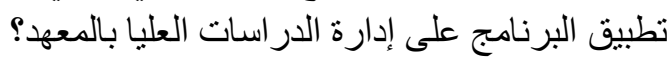

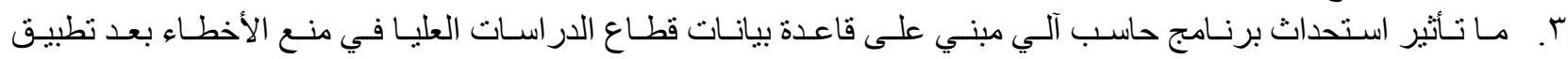

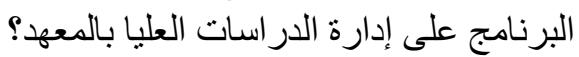

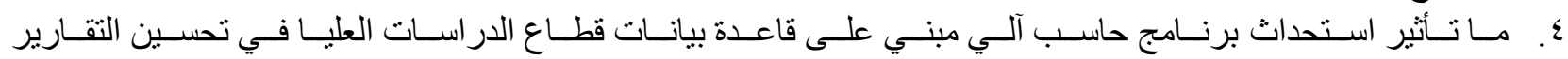
التلخيصية للبيانات بعد تطبيق البرنامج على إدارة الدراسي البات العليا بالمعهد؟

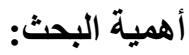

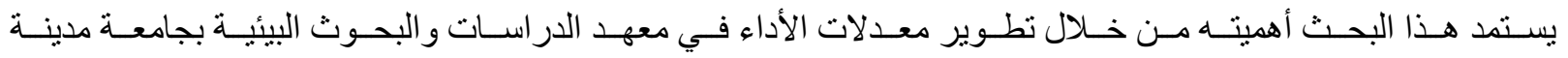

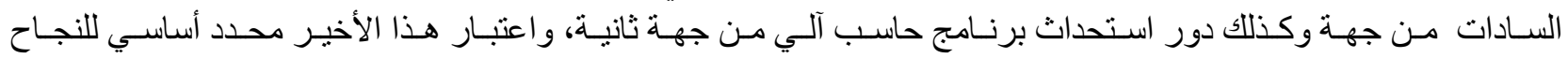
ورصد تحسن الأداء ومنع وتلاشي الأخطاء في ظل التغيير الرقمي ويتمثل ذلك في النقاط التالية:

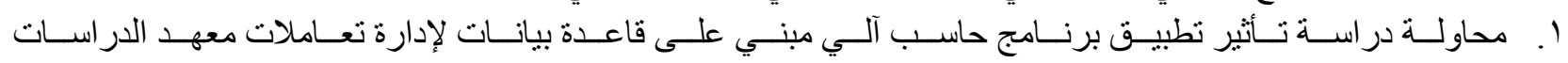

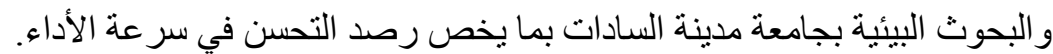

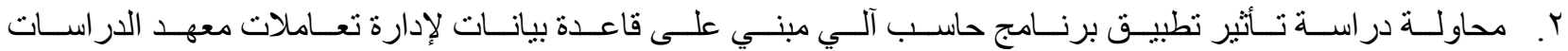

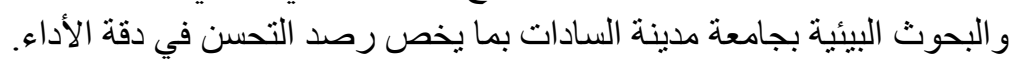

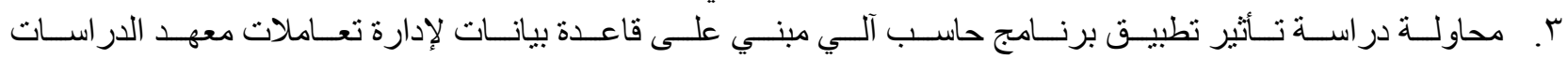

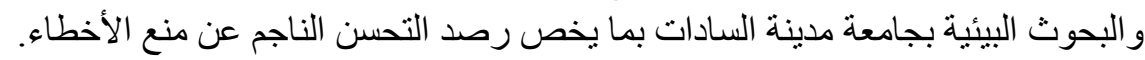

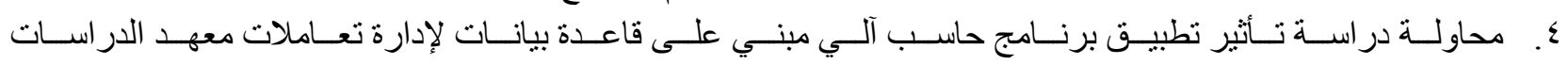
و البحوث البيئية بجامعة مدينة السادات بما يخص رصد رند التحسن في عرض التقارير التلخيصية للبيانات.

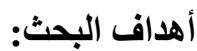

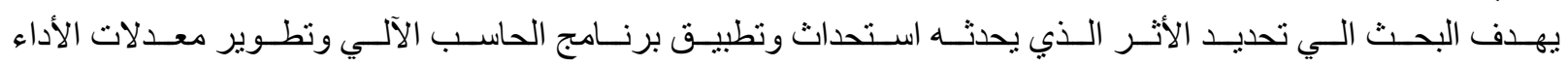

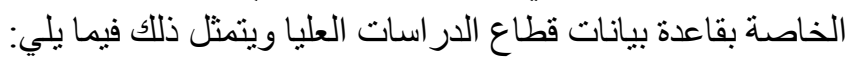




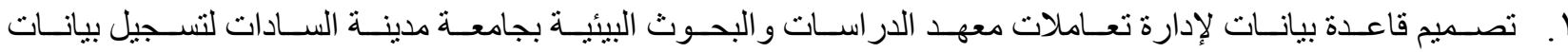

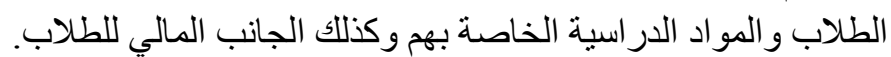

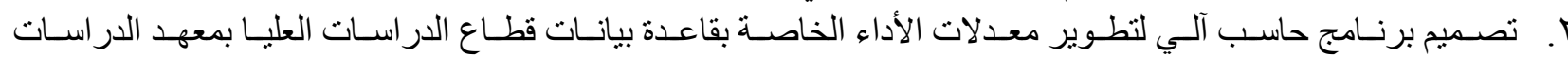

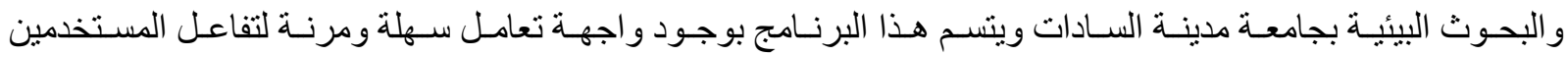

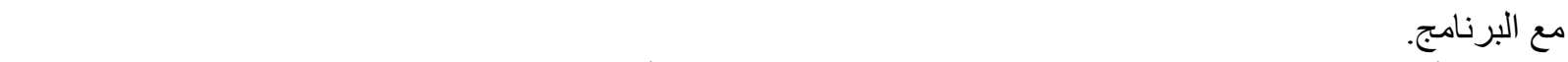

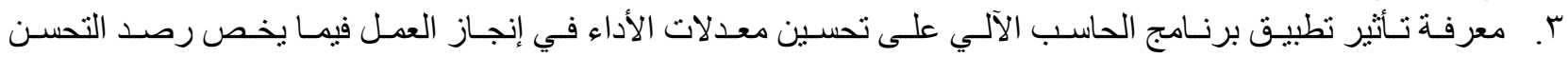
في كل من: سر عة الأداء. دقة الأداء. منع الأخطاء. إستخلاص التقارير. فروض البحث: يمكن صياغة فروض البئ البحث على النحو التالي:

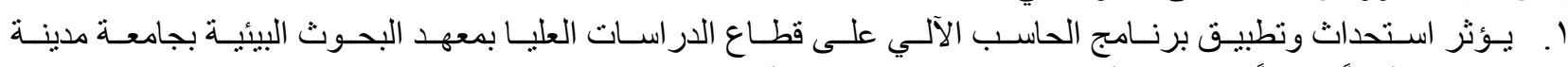

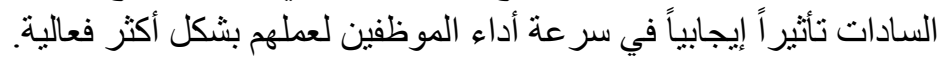

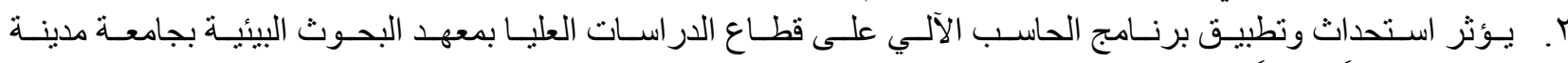

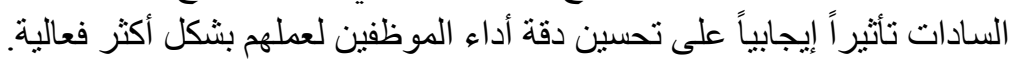

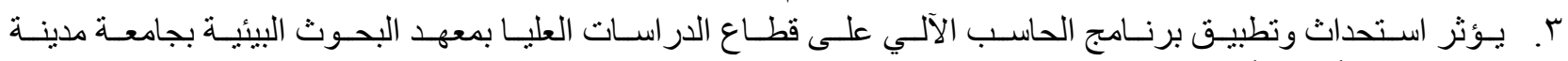

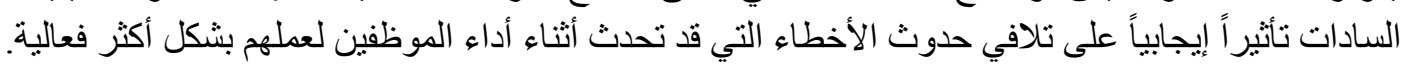

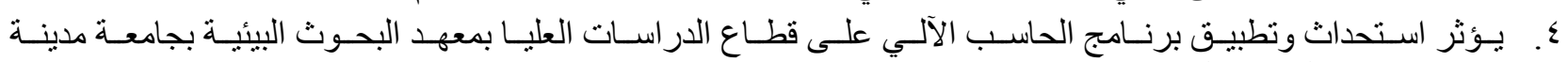

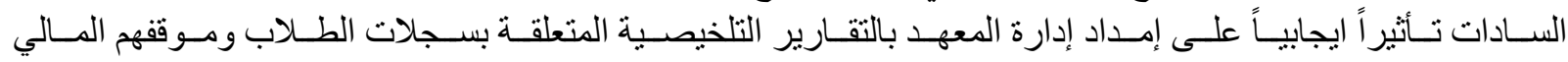
بشكل أكثر فعالية.

\section{مجتمع وعينة البحث:}

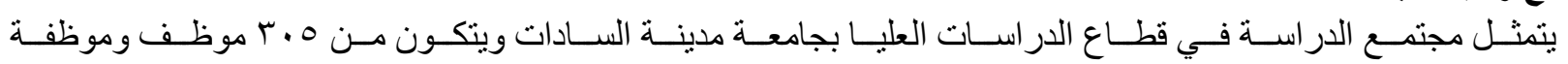

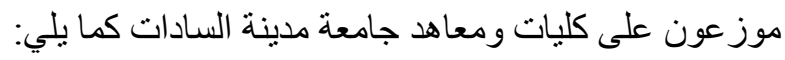

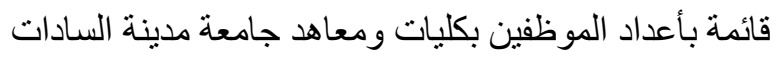

\begin{tabular}{|c|c|c|}
\hline عدد الموظفين & الكلية / المعهد & b \\
\hline$r$. & كلية التربية الرياضية & 1 \\
\hline$r r$ & كلية السياحة والفنادق & r \\
\hline$r r$ & كلية الطب البيطري & $r$ \\
\hline$\varepsilon \varepsilon$ & 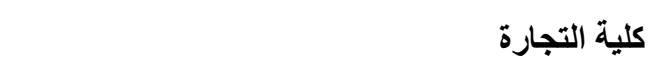 & $\varepsilon$ \\
\hline 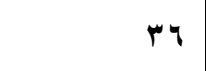 & كلية التربية & 。 \\
\hline$\leq 0$ & كلية الحقوق & 9 \\
\hline 19 & كلية الصيدلة & $v$ \\
\hline$r$ & كلية التربية والطفولة المبكرة & $\wedge$ \\
\hline ro & معهة بحوث الهندسة الوراثية والتكنولوجيا الحيوية & 9 \\
\hline$r \cdot$ & معهد الدراسات والبحوث البيئية & 1. \\
\hline
\end{tabular}




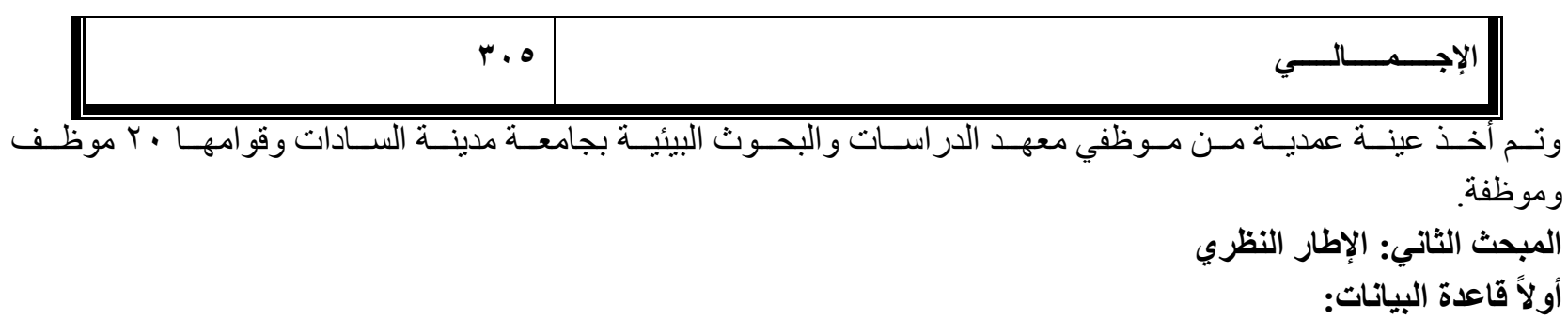

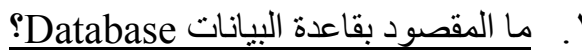

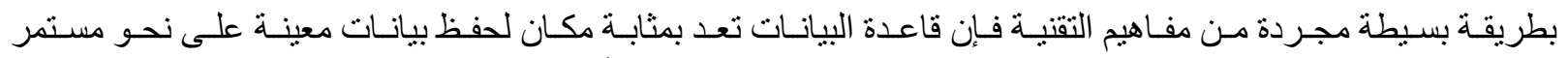

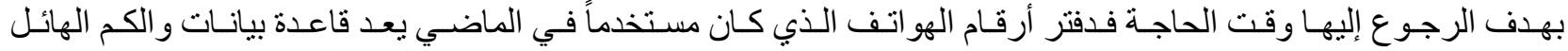

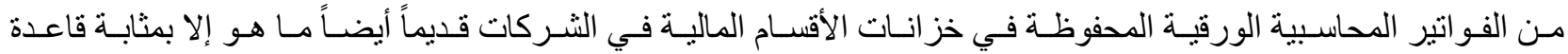

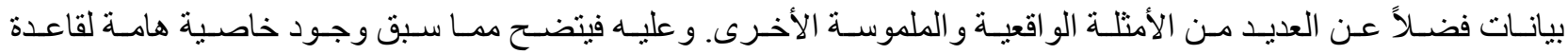
البيانات ألا وهي "الاستمر ارية" أو "الدو ام" في حفظ البيانات.

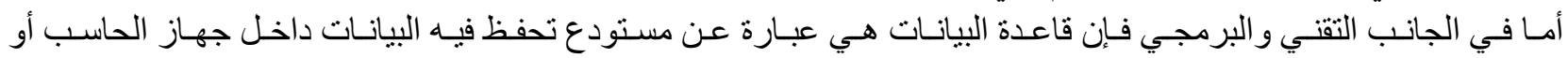

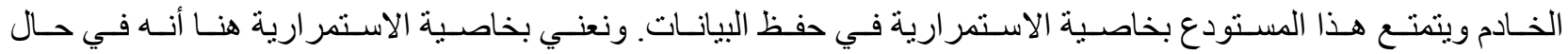

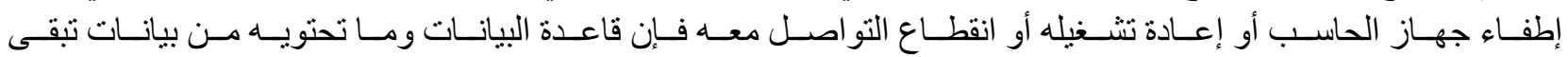

موجودة ومحفوظة دون أي خلل. r. أنظمة إدارة قو اعد البيانات:

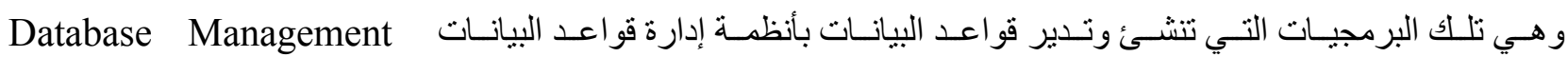
System وتكتب بالاختصار SBMS. r. أنواع أنظمة إدارة قو اعد البيانات:

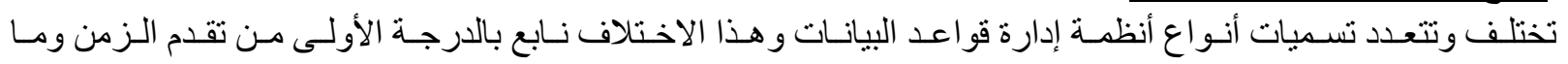

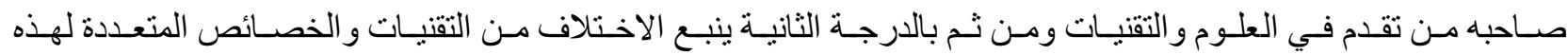
الأنظمة وما تقدمه من خدمات أنقات

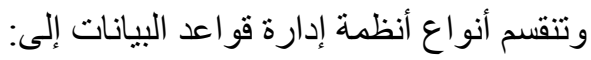

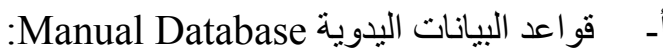

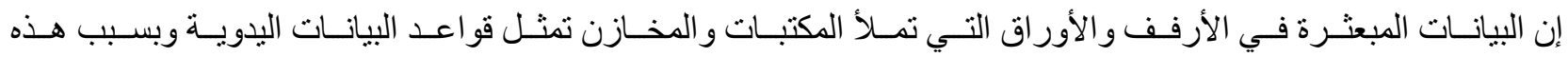

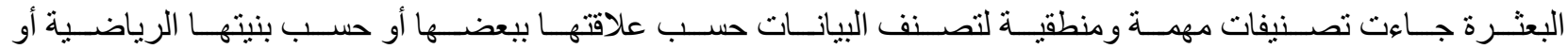

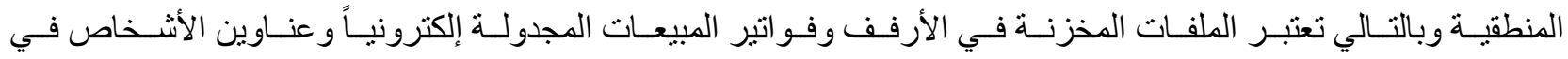
ملف وثائقي أمثلة لبيانات يدوية.

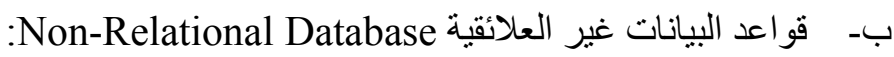

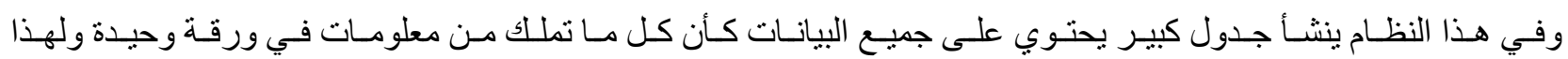

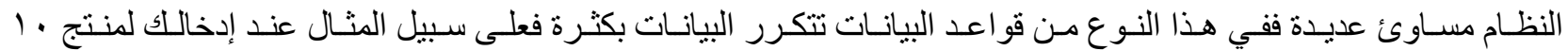

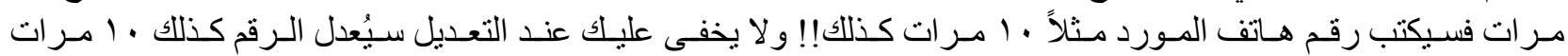
أيضاً!!

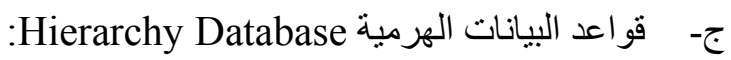

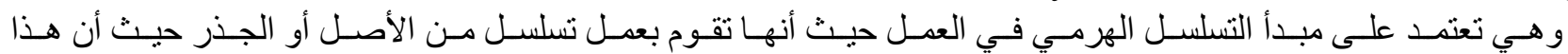

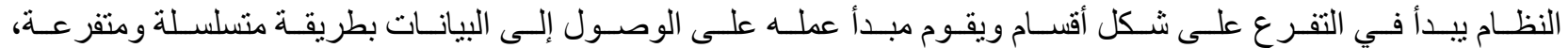
وتكون إما من أسفل للأعلى أو من الأعلى للأسفل.

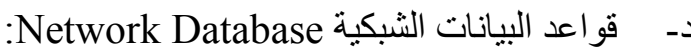

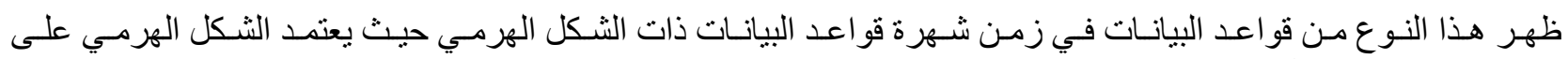

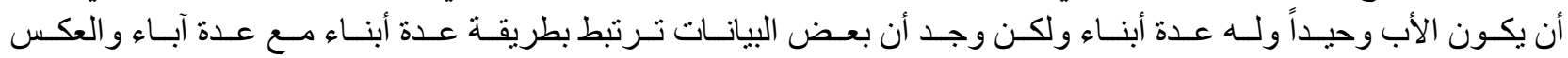

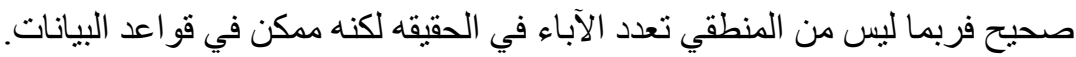

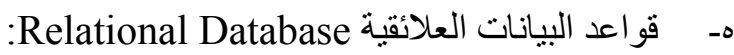




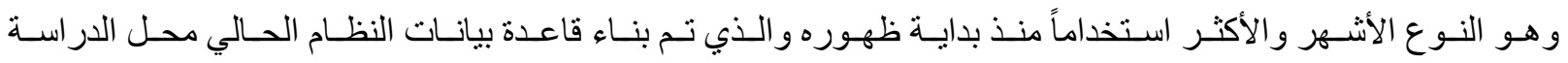

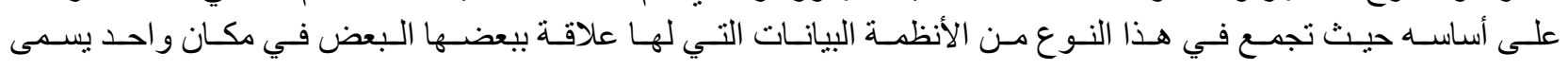

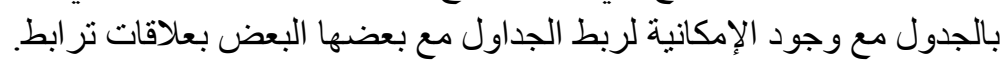

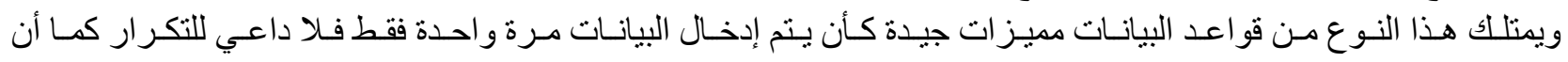

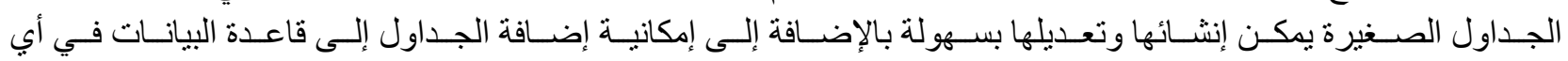

ع. الفرق بين قو اعد البيانات الهرمية و الثبكية و العلائقية:

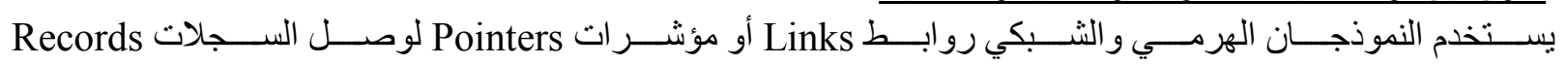

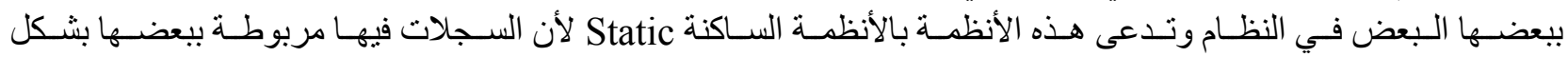

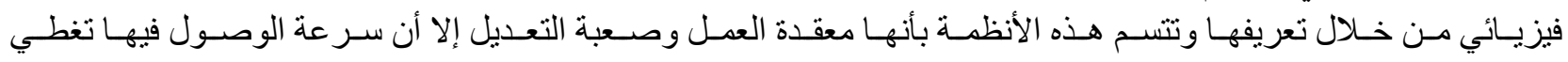
عيوبها.

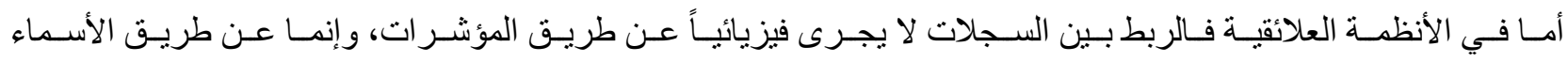

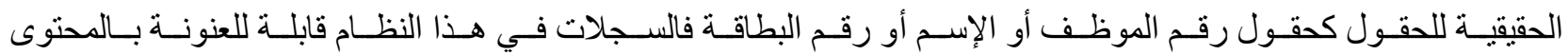
Content-Addressable ه-خصائص قو اعد البيانات العلائقية ومميز اتها:

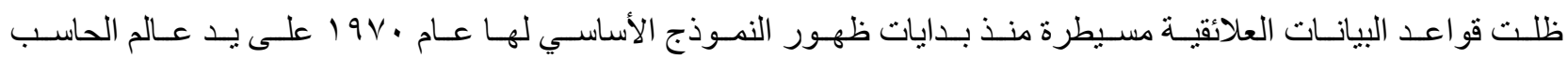

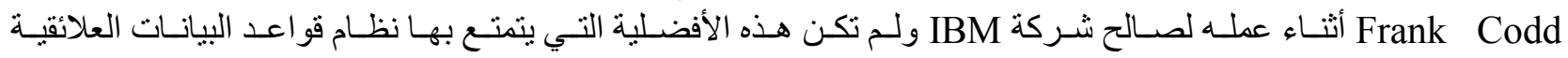
تأتي من فر اغ بل من الخصائص التالية: أ- البساطة ب- - بهولة الاستعلام عن البيانات

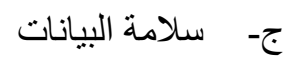
د- ج- المرونة

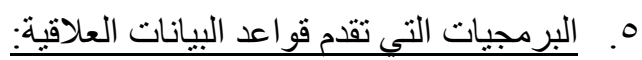

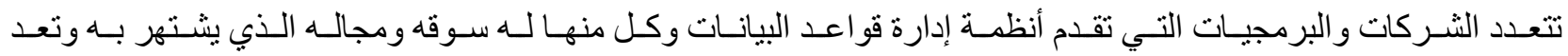

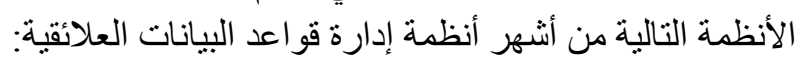

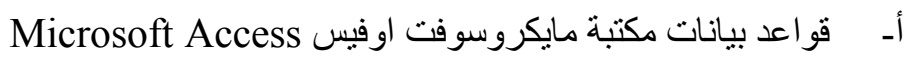

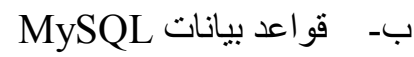

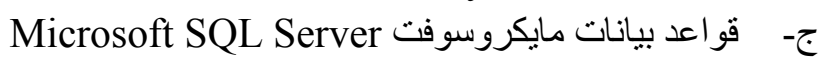

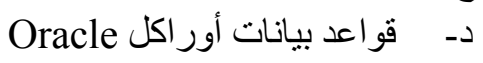

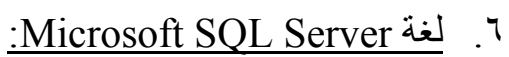

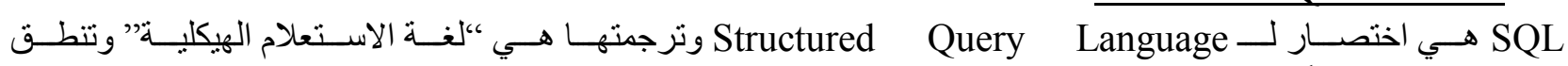

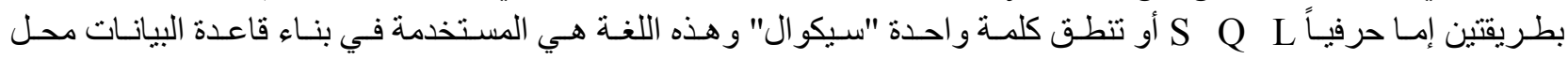
البحث الحالي.

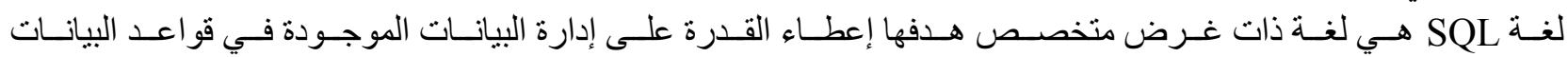

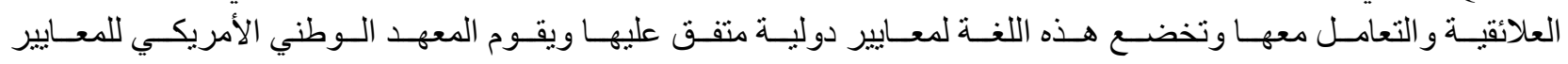

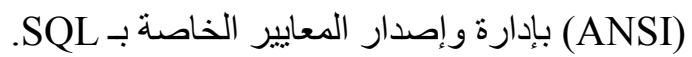

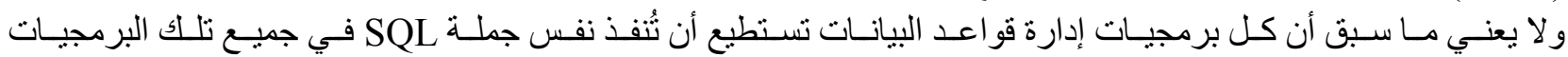

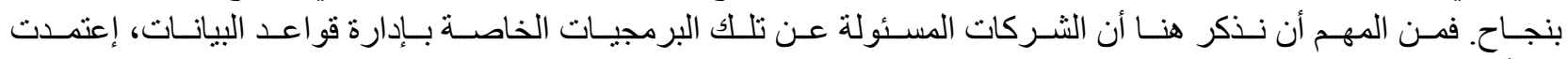

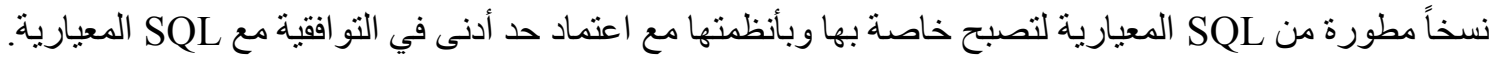

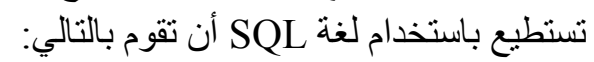
أــ الاستعلام عن البيانات وجلبها من قاعدة البيانات.

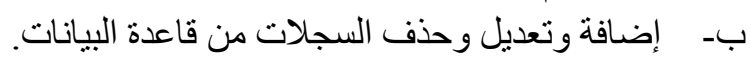
ج- الحفاظ على سلامة ودقة البيانات في قاعدة البيانات. 
د- تحديد الصلاحيات الخاصة بمستخدمي قاعدة البيانات.

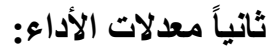

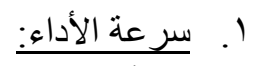

سر عة الأداء هى إنجاز المهام المطلوب تحقيقها فى أقل وقت مع مر اعاة الجودة والكفاءة.

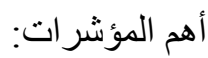

أـ سر عة إدخال السجلات لقاعدة البيانات مقارنة بالتسجيل الورقي أو البدوي.

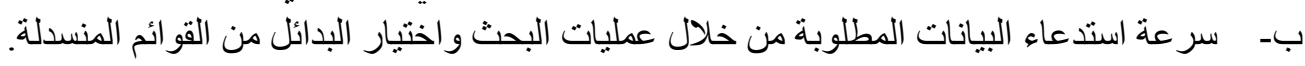

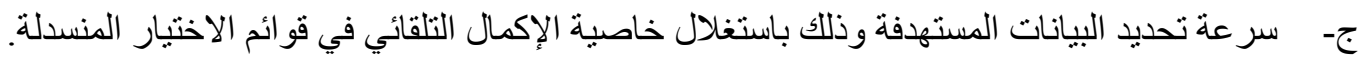
دـ سر عة الوصول لمهام كل مستخدم على حدى عن طريق تحديد صلاحيات مستخدمي النظام.

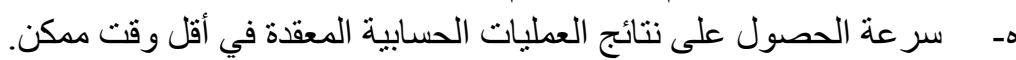

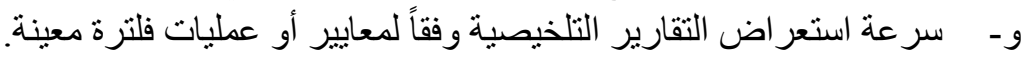

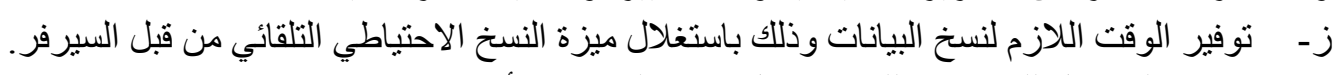

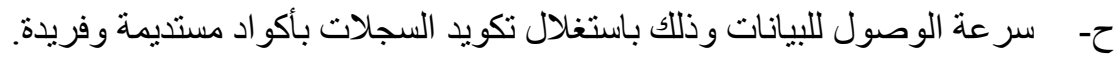

ب. ب. دقة الأداء:

دقة الأداء هي القدرة على تحويل المدخلات إلى مخرجات، و أهداف يسعي النظام لتحقيقها بجودة وكفاءة عالية.

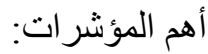

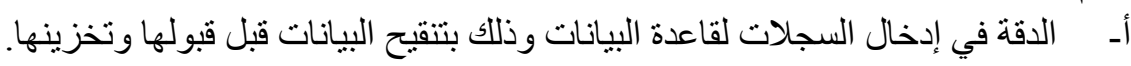

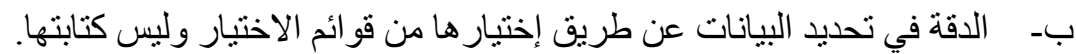

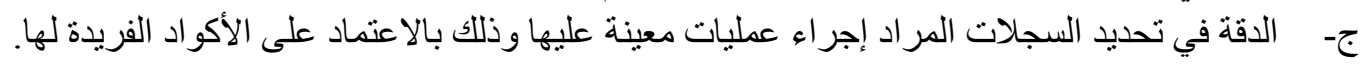

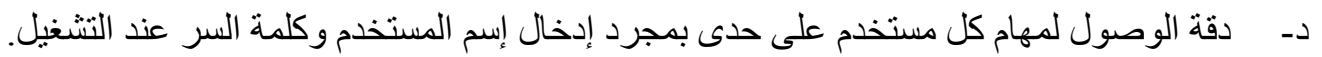

هـ دقة المخرجات الناتجة عن المعالجات الحسابية و المنطقية.

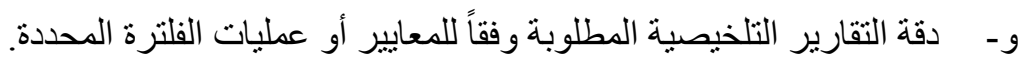

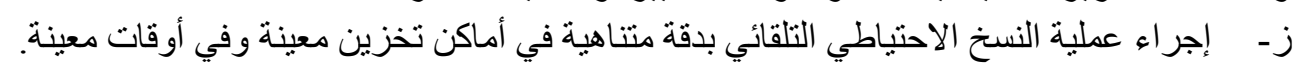

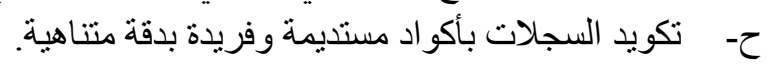

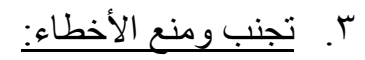

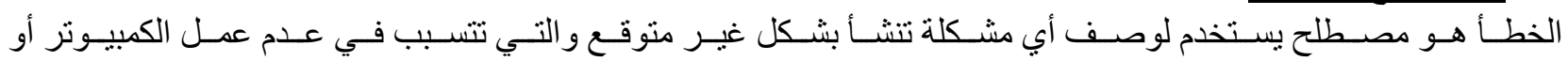

البرنامج بشكل صحيح.

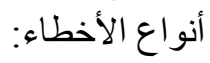

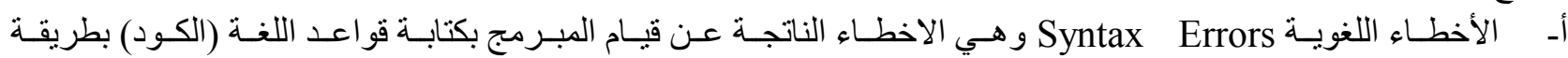

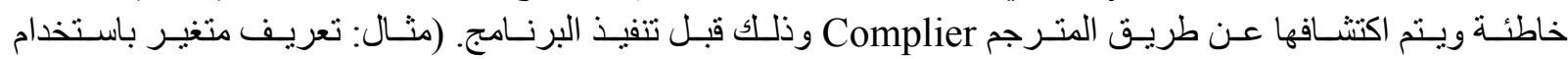
كلمة من الكلمات المحجوزة في اللغة).

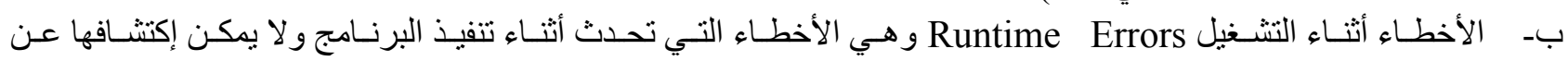

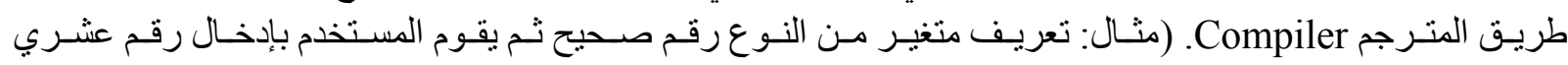
لهذا المتغير).

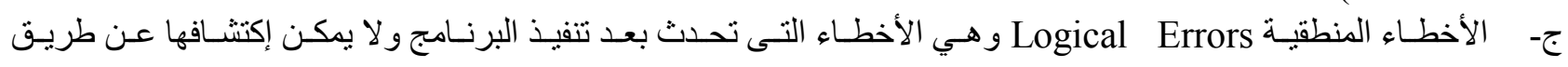
المثرجم Compiler. (مثال: إدخال المستخدم صفر ليقوم البرنامج بالقسمة عليه).

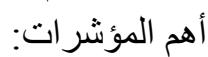

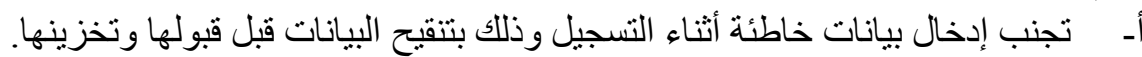

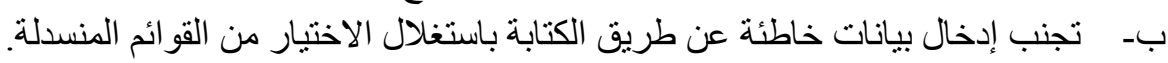

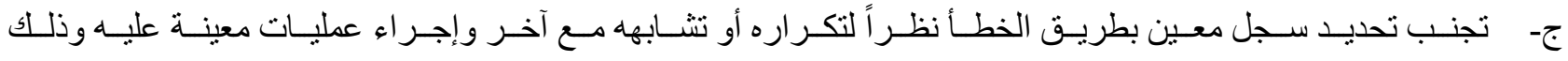
بالاعنماد على الكود الفريد لهذا السجل.

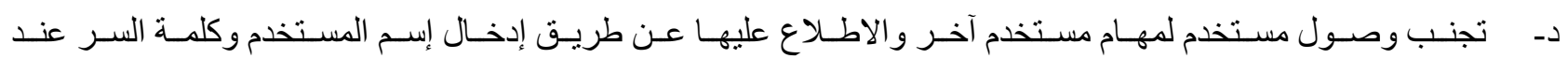
التشغيل. 


$$
\begin{aligned}
& \text { ه- تجنب الحصول على نتائج خاطئة للمخرجات الناتجة من البرنامج. } \\
& \text { و - تجنب الحصول على تقارير تلخيصية بها معلومات خاطئة. }
\end{aligned}
$$

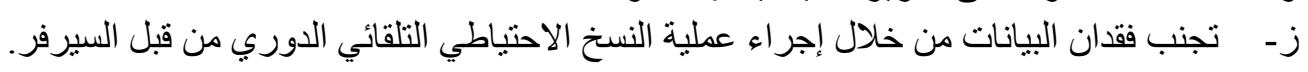

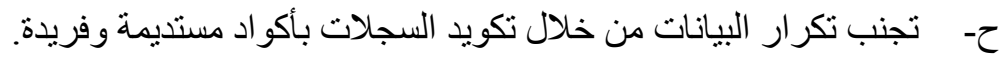

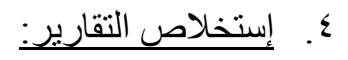

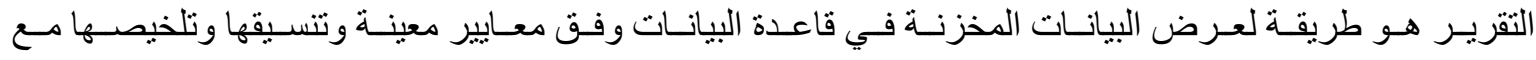

امكانية طباعتها.

أهم المؤشرات:

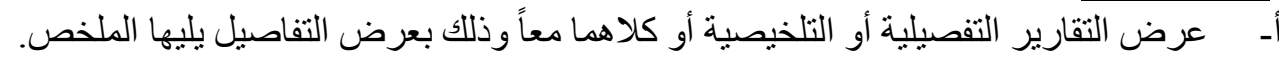

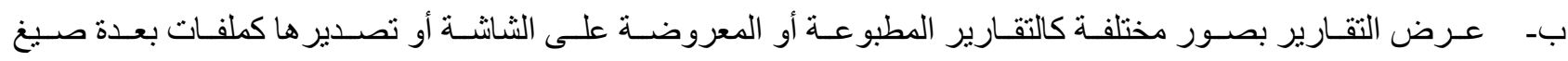

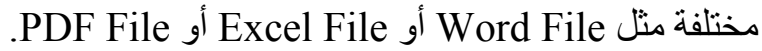
ج- عرض تقارير البيانات بتنسيقات عديدة الخطوط الألوان و الحدود و الر أس و التذييل وترقيم الصفحات.

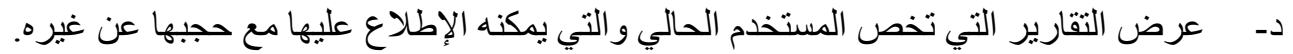
هـ عرض التقارير بناء على معايير معينة يقوم المستخدم بتحديدها أو الفلترة على أساسها.

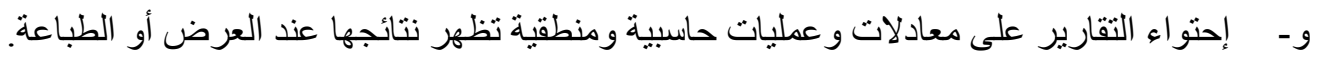

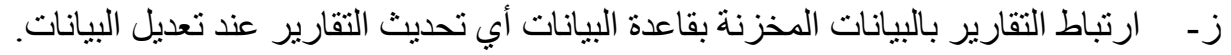

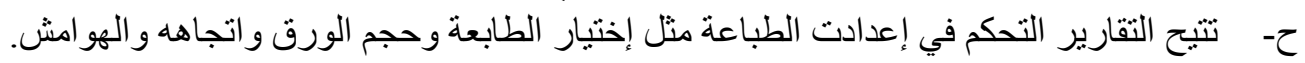

$$
\begin{aligned}
& \text { ثالثاً برنامج الحاسب الآلي: }
\end{aligned}
$$

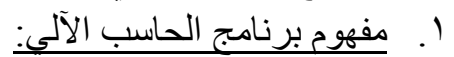

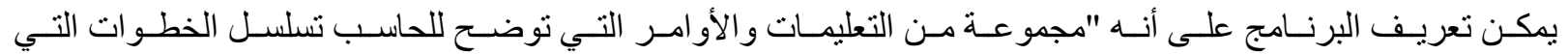

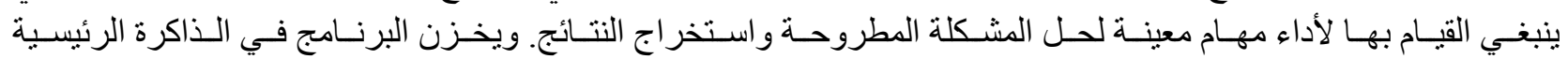

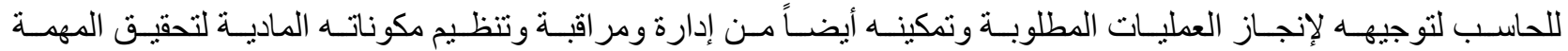
المطلوبة".

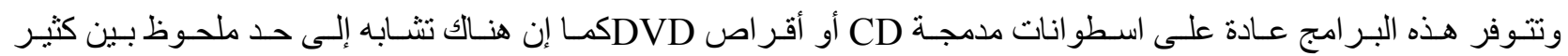

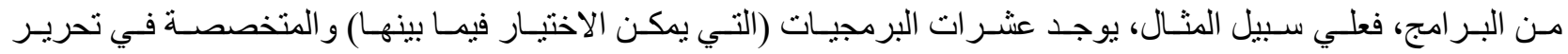

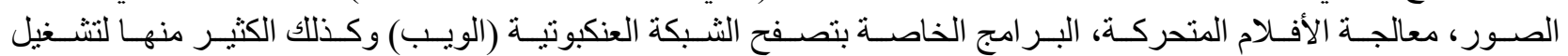
الفيديو. وكل تللك البرمجيات منشابهة إلي حد كبير في الوظائف و المهام التي تسنطيع القيام بها.

$$
\text { تبقَّ برمجيات الحاسب: }
$$

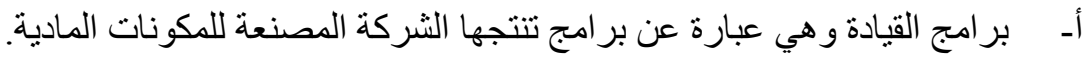

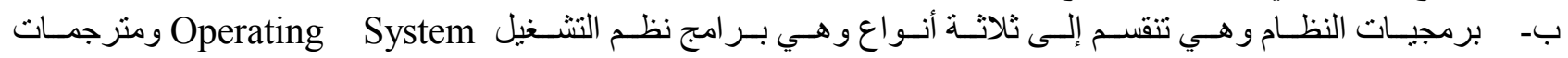
اللغات Compilers / Interpreters و البر امج المساعدة Stility Programs.

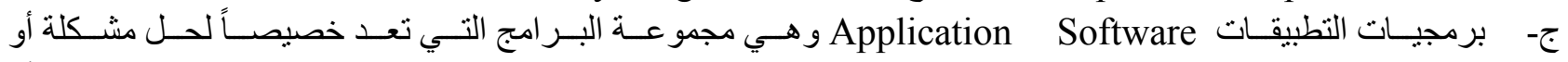

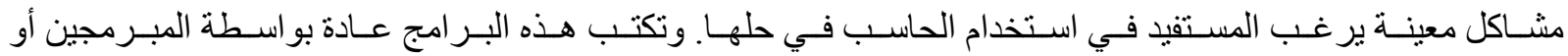
الحصول عليها من بيت من بيوت الخبرة المتخصصة في هذا المجال.

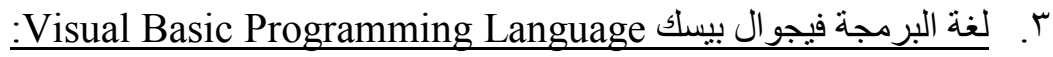

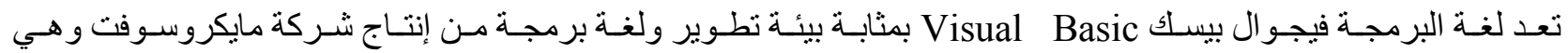

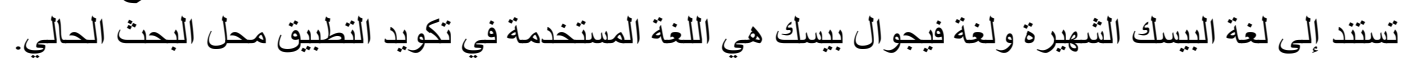

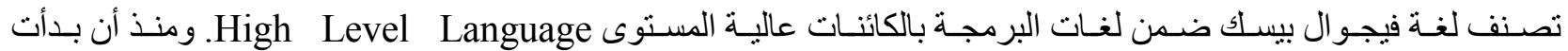

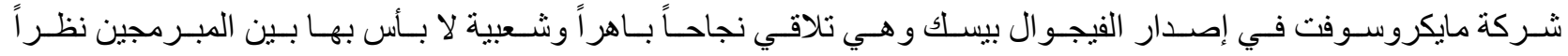

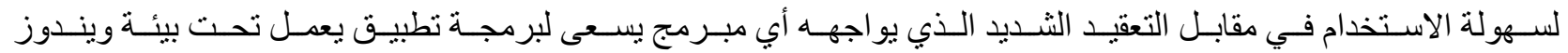

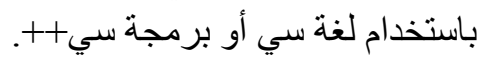




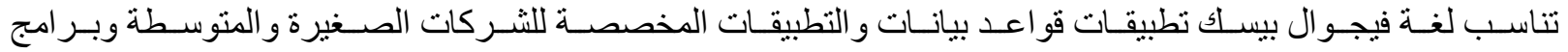

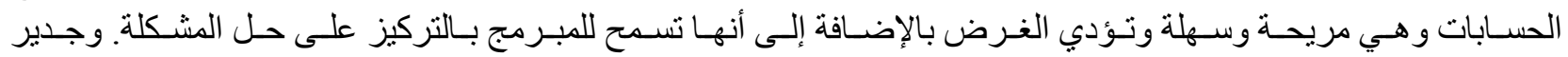

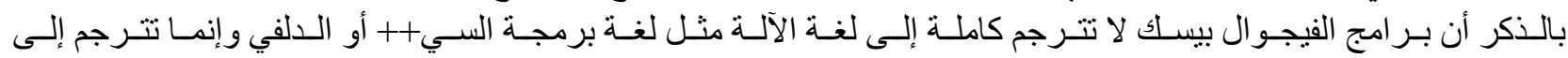

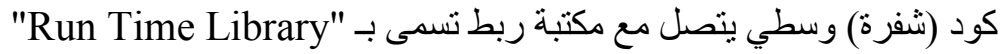

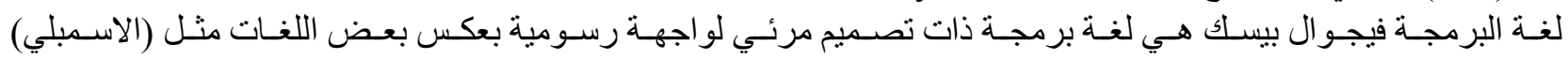

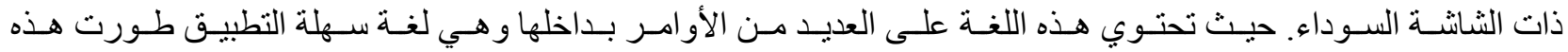

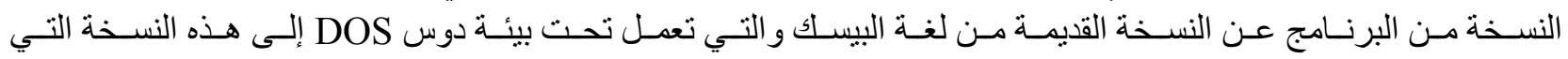

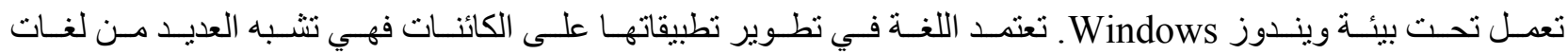

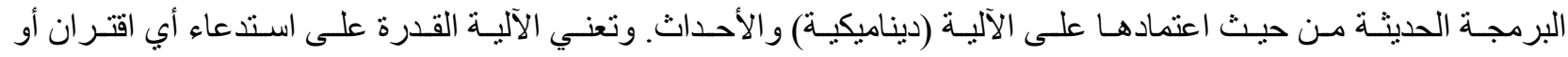

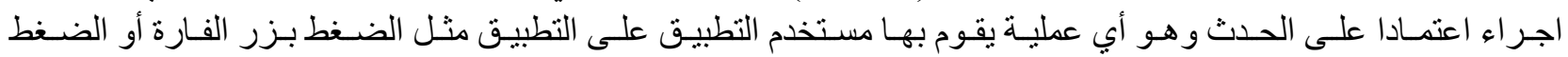

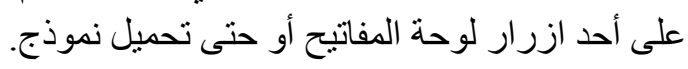

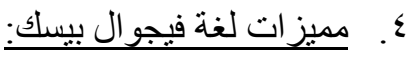

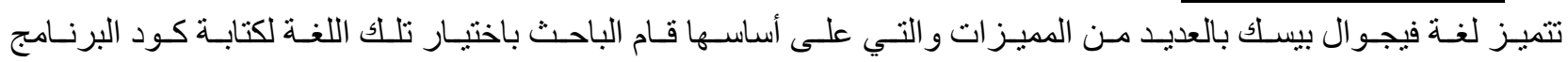

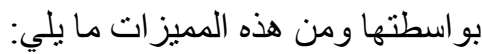

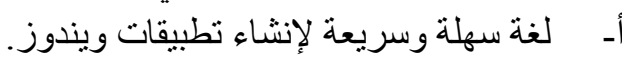
ب- ت تدعم البرمجة الثبيئية. ج- ت تعتبر لغة الفيجو ال بيسك لغة كائنة د- سهلة التعلم و الفهم. ه- ـ سهولة اكتشاف الأخطاء فيها.

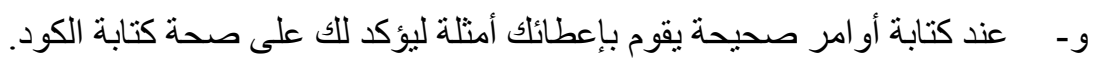
ز - تمكنك من تخطي بعض الأخطاء عند كتابة كود محدد. المبحث الثالث: الجانب الإحصائي ومناقشة النتائج

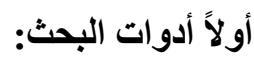

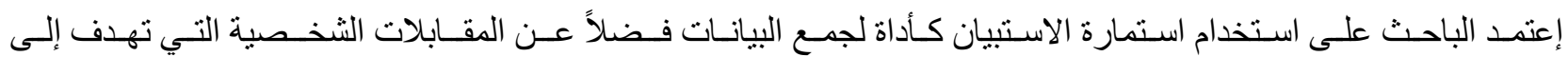

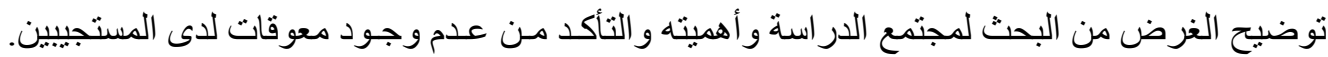

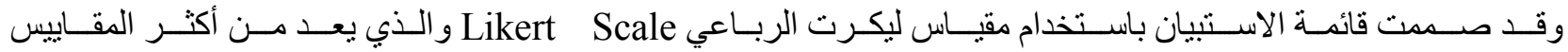

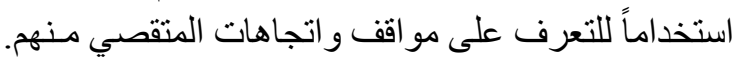

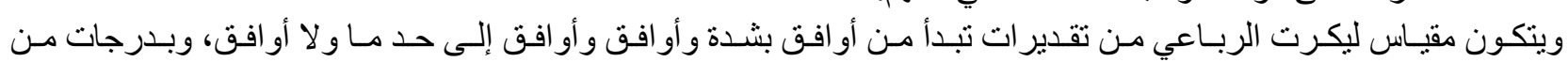

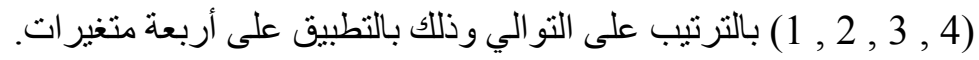
ثانياً متغيرات البحث: البر 1. . متغير سرعة الأداء ويتم قياسه من خلال عثرة أبعاد في استمارة الاستبيان.

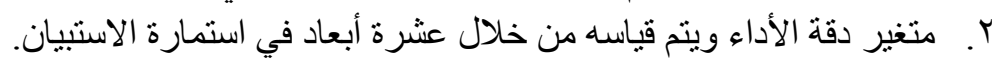

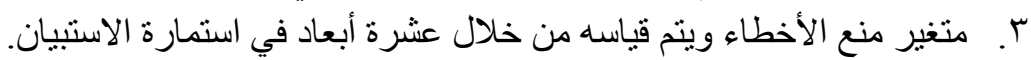

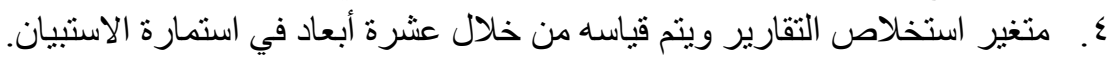
ثالثاً الأساليب الإحصائية للبحث:

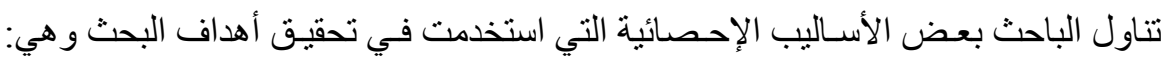

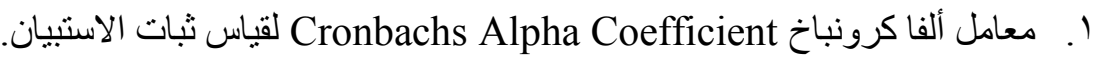

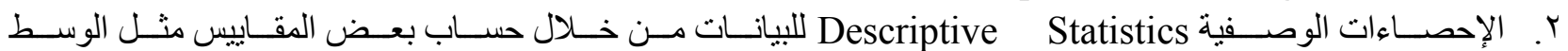

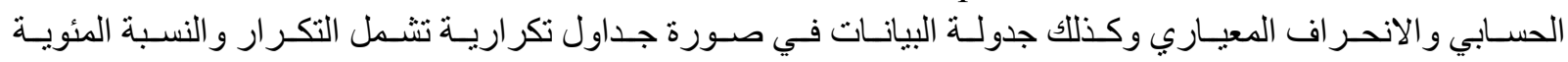
وذللك لتحديد سمات اتجاهات استجابات مفردات عينة البحث.

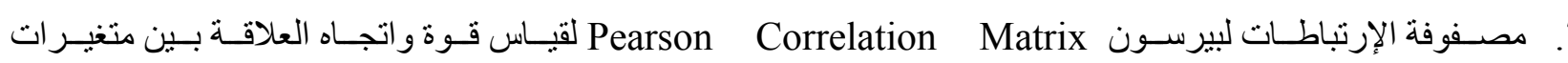
البحث كما تم قياس معنوية معاملات الإرتباط. ؛. إختبار t (ت) لعينتين غير مستقلتين. 
رابعاً إختبارات الصدق والثبات:

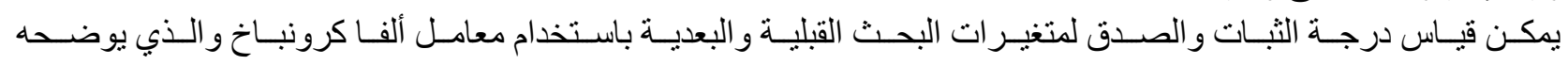
الجدول التالي:

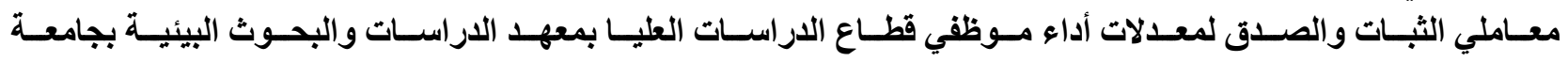
مدينة السادات (للمتغيرات القبلية)

\begin{tabular}{|c|c|c|c|}
\hline معامــــ الصدق & معامل الثبات & عدد العبار ات & بيان بيان \\
\hline$\cdot, \wedge 1$ &., 70 & 1. & سر عة الأداء \\
\hline$\cdot, \Lambda Y$ & $\cdot, 7 V$ & 1. & دقة الأداء \\
\hline$\cdot, \wedge \mu$ &., 79 & 1. & منع الأخطاء \\
\hline$\cdot, \wedge \varepsilon$ & $\cdot, V \cdot$ & $1 \cdot$ & إستخلاص التقارير \\
\hline$\cdot, \wedge 9$ & $\cdot, \wedge \cdot$ & $\varepsilon$ & \\
\hline
\end{tabular}

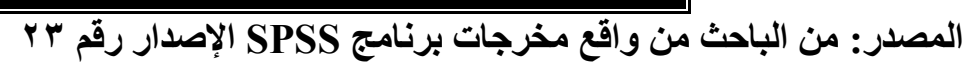

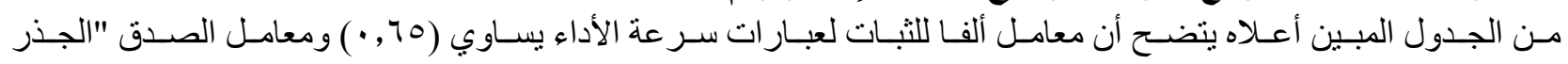

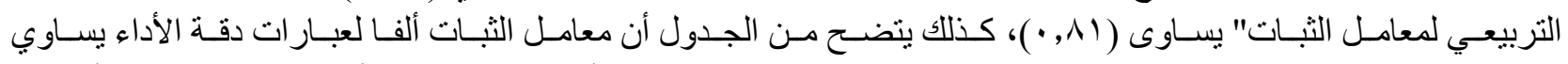

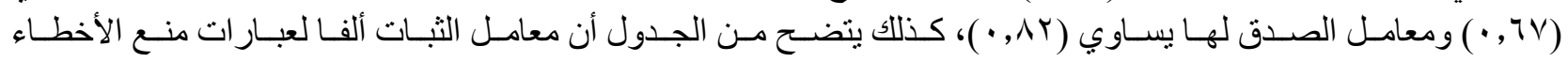

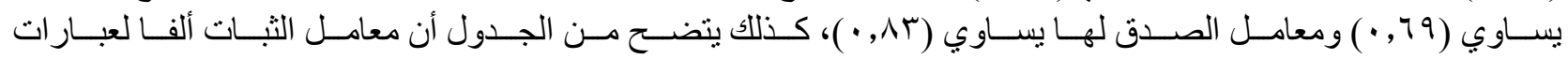

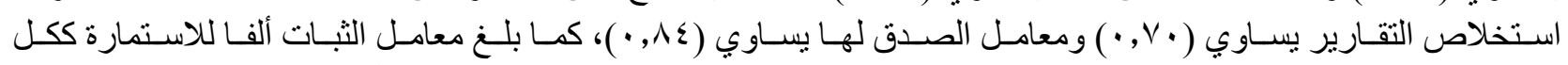

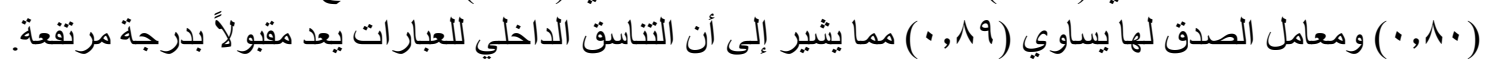

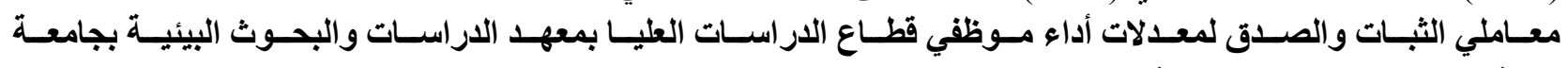

مدينة السادات (للمتغيرات البعدية)

\begin{tabular}{|c|c|c|c|}
\hline معامــــ & معامل الثبات & عدد العبار ات & البيان \\
\hline$\cdot, \wedge 0$ & $\cdot, V Y$ & 1. & سر عة الأداء \\
\hline •,АT & $\cdot, V \cdot$ & 1 . & دقة الأداء \\
\hline$\cdot, \wedge 7$ & $\cdot, V \leqslant$ & 1. & منع الأخطاء \\
\hline$\cdot, 9$. & $\cdot, \wedge 1$ & 1. & إستخلاص التقارير \\
\hline., 94 & $\cdot, \wedge \vee$ & $\varepsilon$. & \\
\hline
\end{tabular}

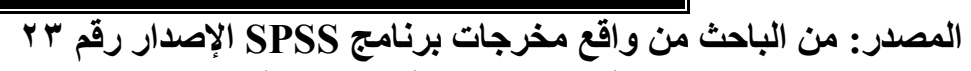

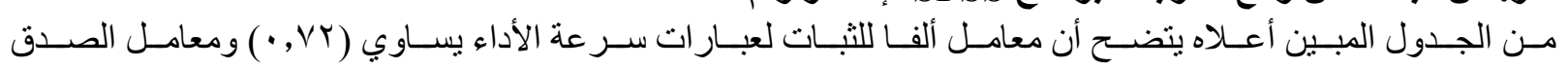

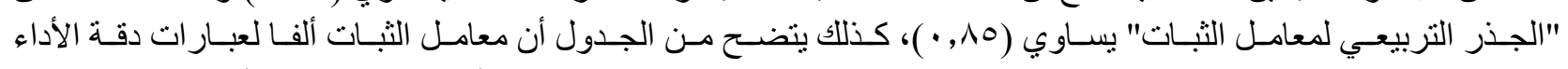

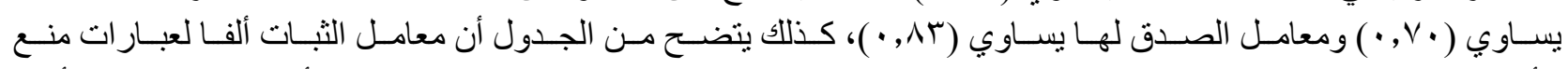

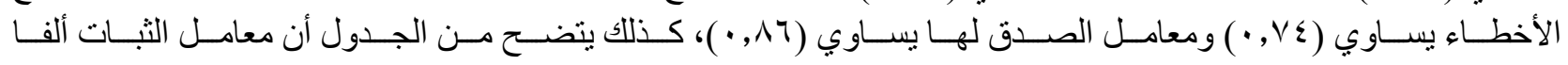

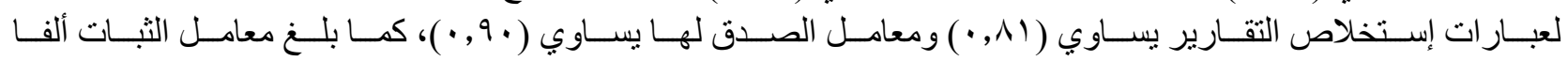

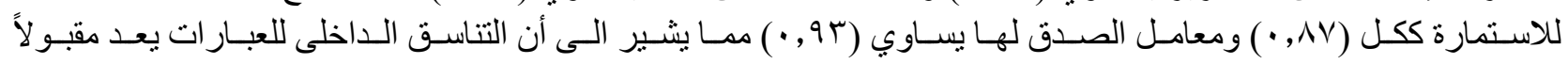
بدرجة مرتفعة. خامساً وصف عينة البحث:

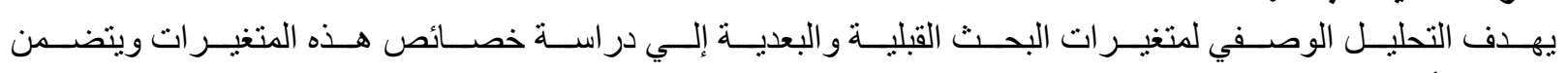

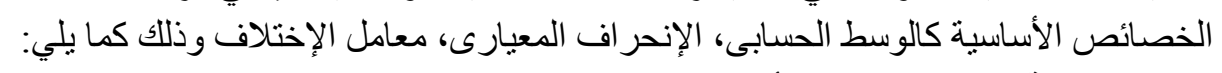

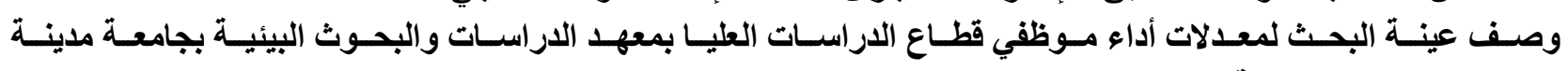
السادات (للمتغيرات القبلية) 


\begin{tabular}{|c|c|c|c|}
\hline معامل الإختلاف & الإنحر اف المعياري & الوسط الحسابي & 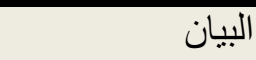 \\
\hline$\% 11,19$ &., 10 & I, & سر عة الأداء \\
\hline$\% 11$ &., 10 & $1, r v$ & دقة الأداء \\
\hline$\% 9, r$ & $\cdot, 1 T$ & $1, r \leqslant$ & منع الأخطاء \\
\hline$\% 1 \cdot, V$ & $\cdot, 10$ & $1, \varepsilon$ & استخلاص التقارير \\
\hline
\end{tabular}

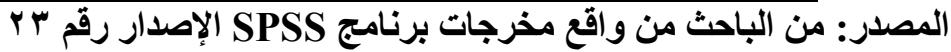

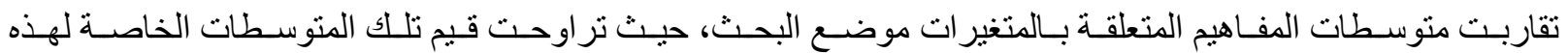

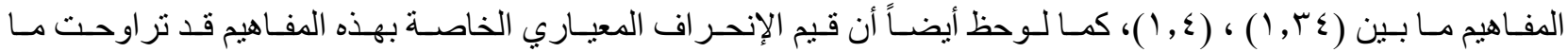

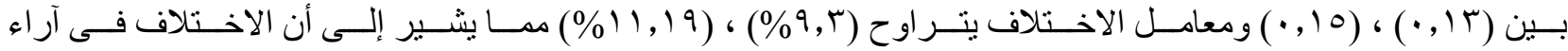

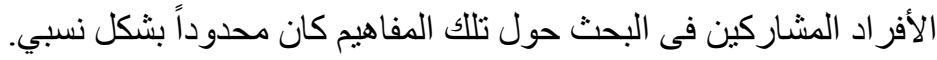

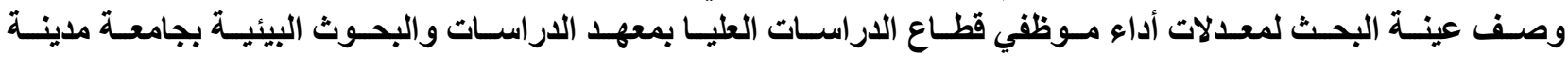
السادات (للمتغيرات البعدية)

\begin{tabular}{|c|c|c|c|}
\hline معامل الإختلاف & الإنحر اف المعياري & الوسط الحسابي & البيان \\
\hline$\% \varepsilon, \wedge 0$ & $\cdot, 11$ & $r, v$ & سر عة الأداء \\
\hline$\% \Gamma, \leqslant 0$ & $\cdot, 1 \pi$ & $r, V V$ & دقة الأداء \\
\hline$\% \Upsilon, \vee$ & $\cdot, 1 \leq$ & $r, \vee \wedge$ & منع الأخطاء \\
\hline$\% \varepsilon$ &., 10 & $r, V \mu$ & استخلاص التقارير \\
\hline
\end{tabular}

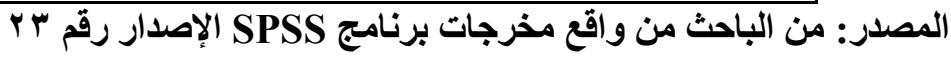

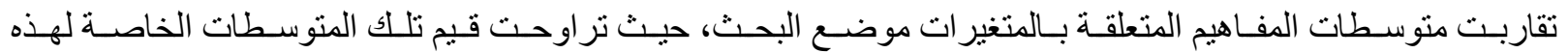

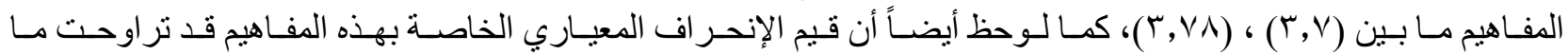

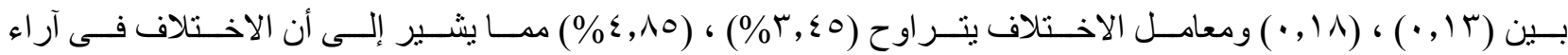

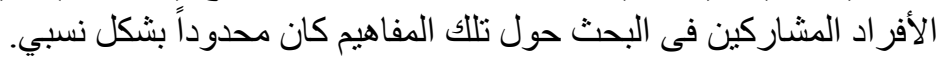

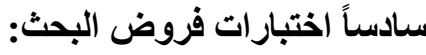

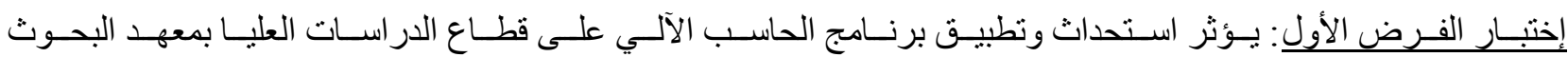

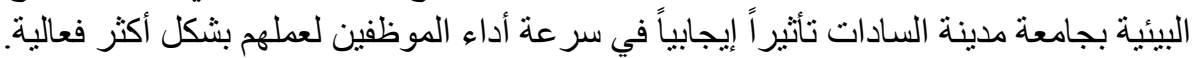

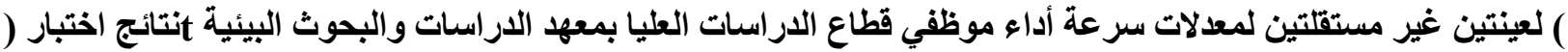
بجامعة مدينة السادات

\begin{tabular}{|c|c|c|c|c|}
\hline القيمة الاحتمالية (sig) & & 1المتوسط & درجات الحرية (df) & قيمة (t) المحسوبة \\
\hline - & بعد TV,TV & قبل ع ז, & 19 & -64.52 \\
\hline
\end{tabular}

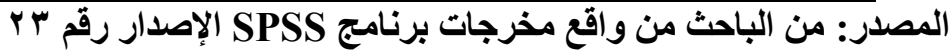

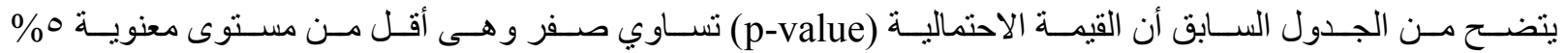

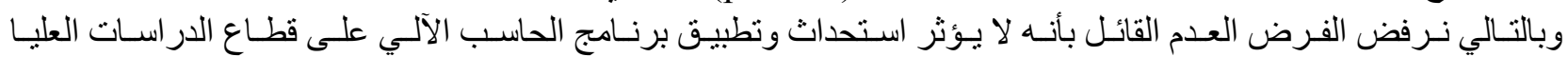

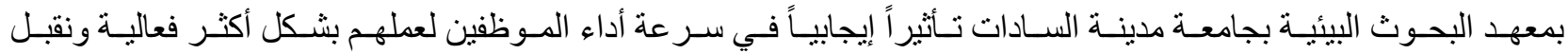

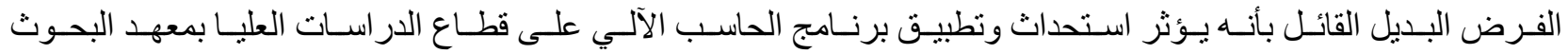

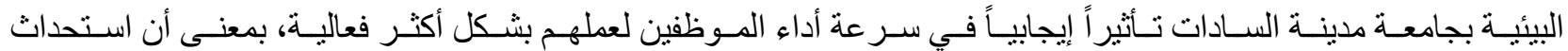

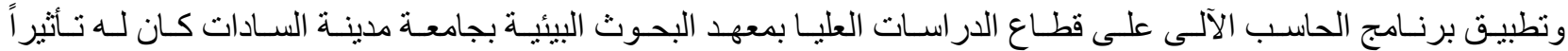

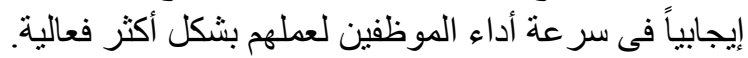

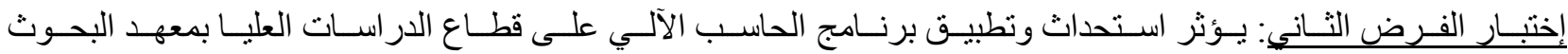
البيئية بجامعة مدينة السادات تأثير اً إيجابياً على تحسين دقة أداء الموظفين لعملهم بشكل أكثر فعالية. 


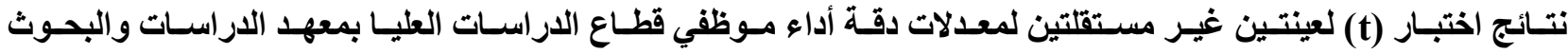

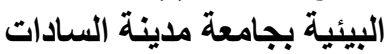

\begin{tabular}{|c|c|c|c|c|}
\hline القيمة الاحتمالية (sig) & & 1المتوسط & درجات الحرية (df) & قيمة (t) المحسوبة \\
\hline - & بعد r,VV & قبل Vr, & 19 & -50.86 \\
\hline
\end{tabular}

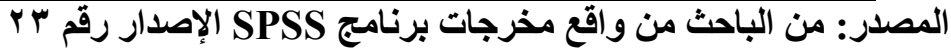

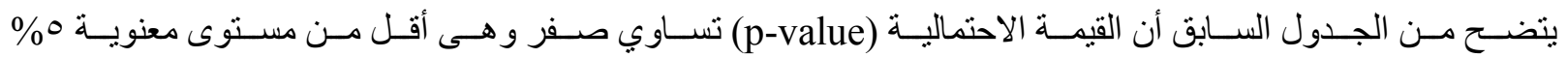

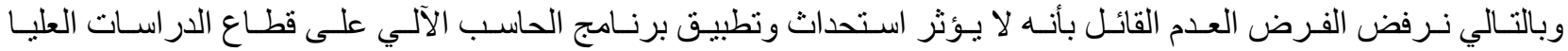

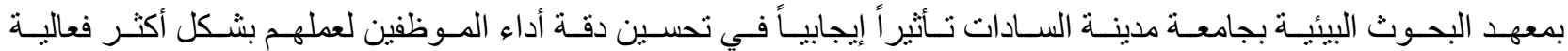

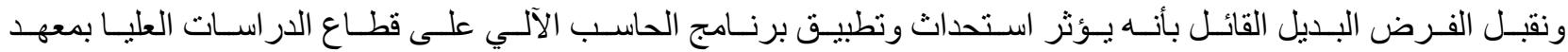

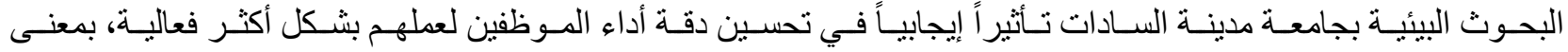

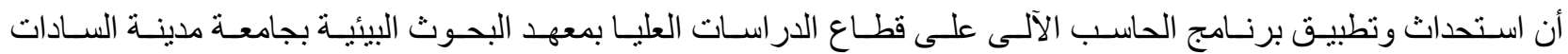

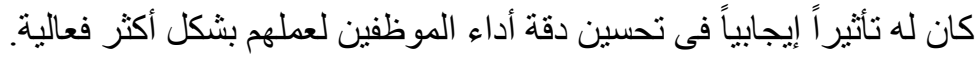

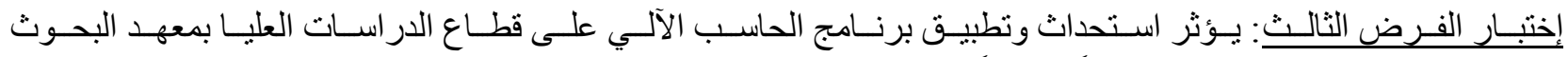

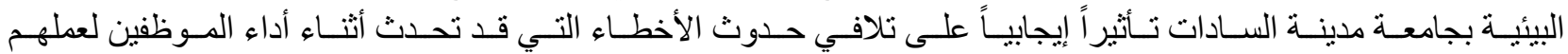
بشكل أكثر فعالية.

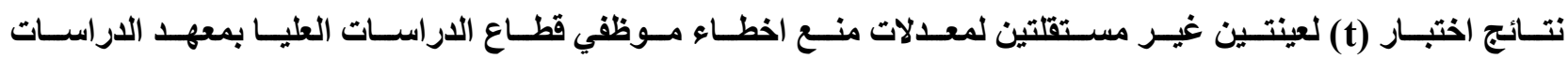
والبحوث البيئية بجامعة مدينة السادات

\begin{tabular}{|c|c|c|c|c|}
\hline القيمة الاحتمالية (sig) & $(\mathrm{M}$ & 1) المتوسط & درجات الحرية (df) & قيمة (t) المحسوبة \\
\hline • & بعد & قبل • ع, 1 & 19 & -49.41 \\
\hline
\end{tabular}

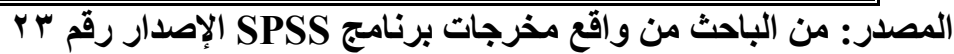

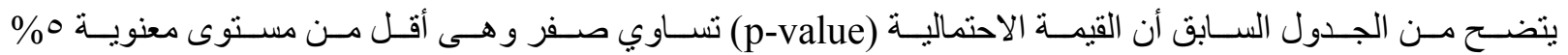

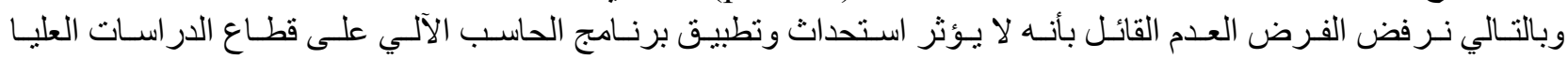

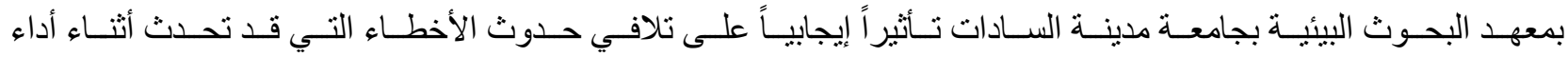

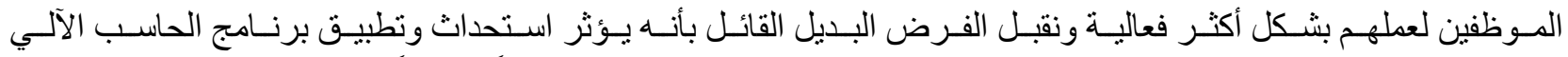

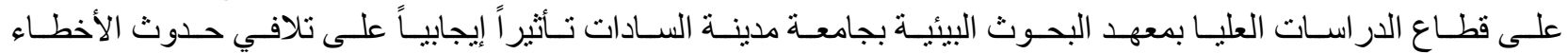

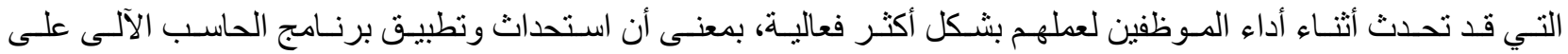

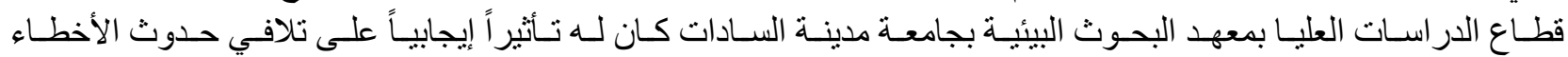
التي قد تحدث أثناء أداء الموظفين لعملهم بشكل أكثر فعالية.

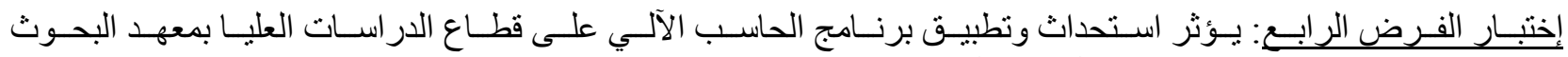

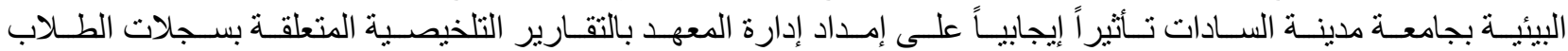
وموقفهم المالي بشكل أكثر فعالية.

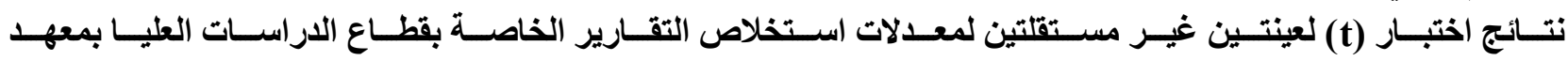
الاراسات والبحوث البيئية بجامعة مدينة السادات

\begin{tabular}{|c|c|c|c|c|}
\hline القيمة الاحتمالية (sig) & $(\mathrm{M}$ & 1) المتوسط & درجات الحرية (df) & قيمة (t) المحسوبة \\
\hline • & بعد • ب,V & قبل • ع, 1 & 19 & -71.64 \\
\hline
\end{tabular}

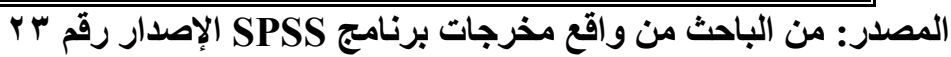

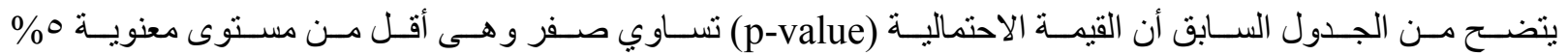

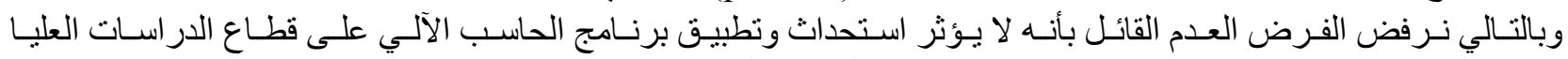

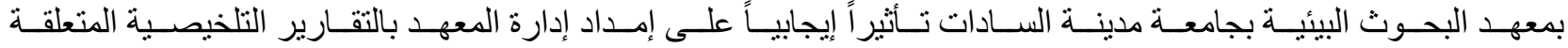

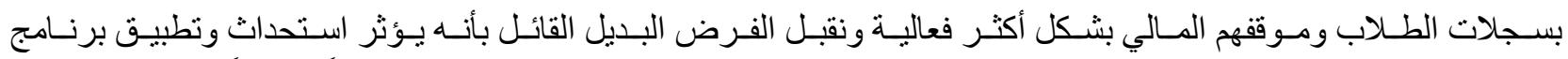

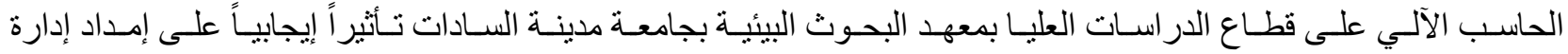

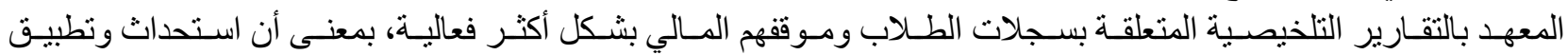




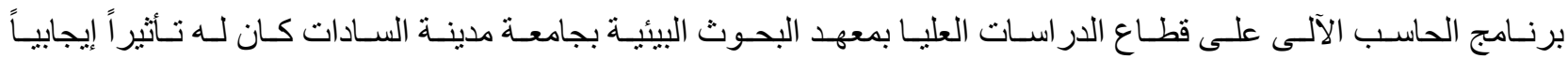
على إمداد إدارة المعهد بالتقارير التلخيصية المتعلقة بسجلات الطلاب وموقفهم المالي بشكل أكثر فعالية.

\section{المبحث الرابع: نتائج وتوصيات البحث}

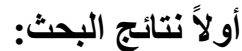

من النتائج السابقة يتضح أنه تم إثبات صحة الفروض النّات الأبعة المشار إليها عاليه:

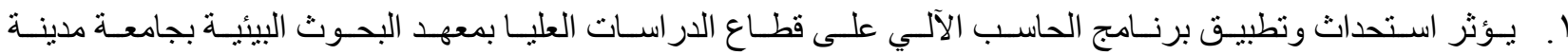

السادات تأثير اً إيجابياً في سرعة أدراء الموظفين لعملهم بشكل أكثر فعالية.

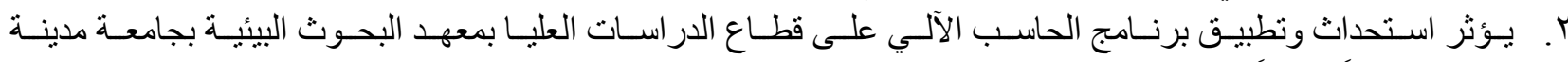

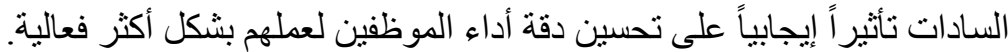

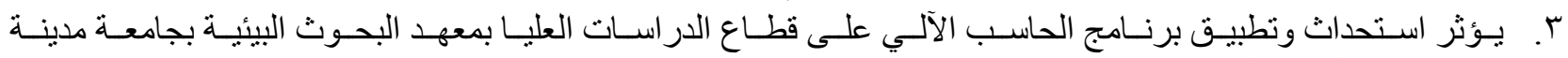

السادات تأثثر أ إيجابياً على تلافي حدوث الأخطاء التي قد تحدث أثناء أداء الموظفين لعملهم بثكل أكثر فعالية.

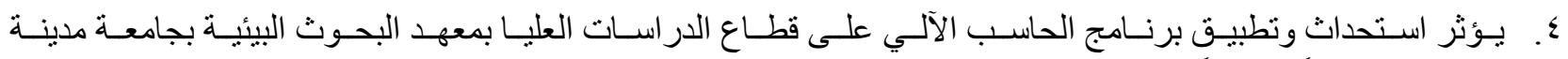

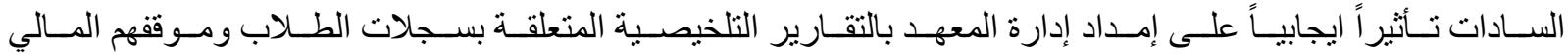
بشكل أكثر فعالية.

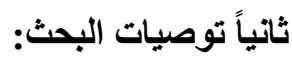

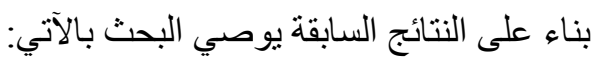

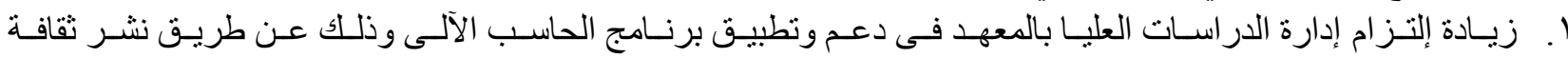
استخدام البرنامج بين الموظفين.

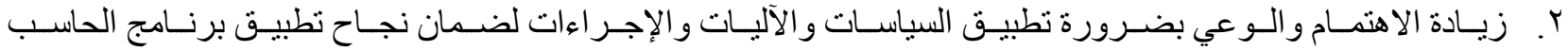
الآلى. ז. ضرورة التركيز و الاهنمام بوضع الخطط الواضحة حول تطبيق برنامج الحاسب الآلى.

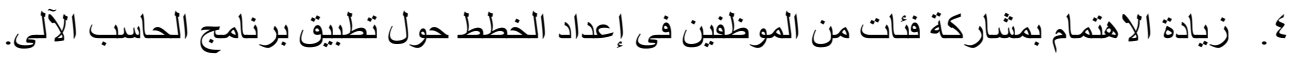

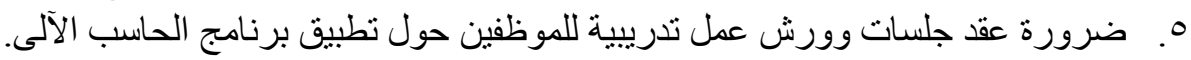

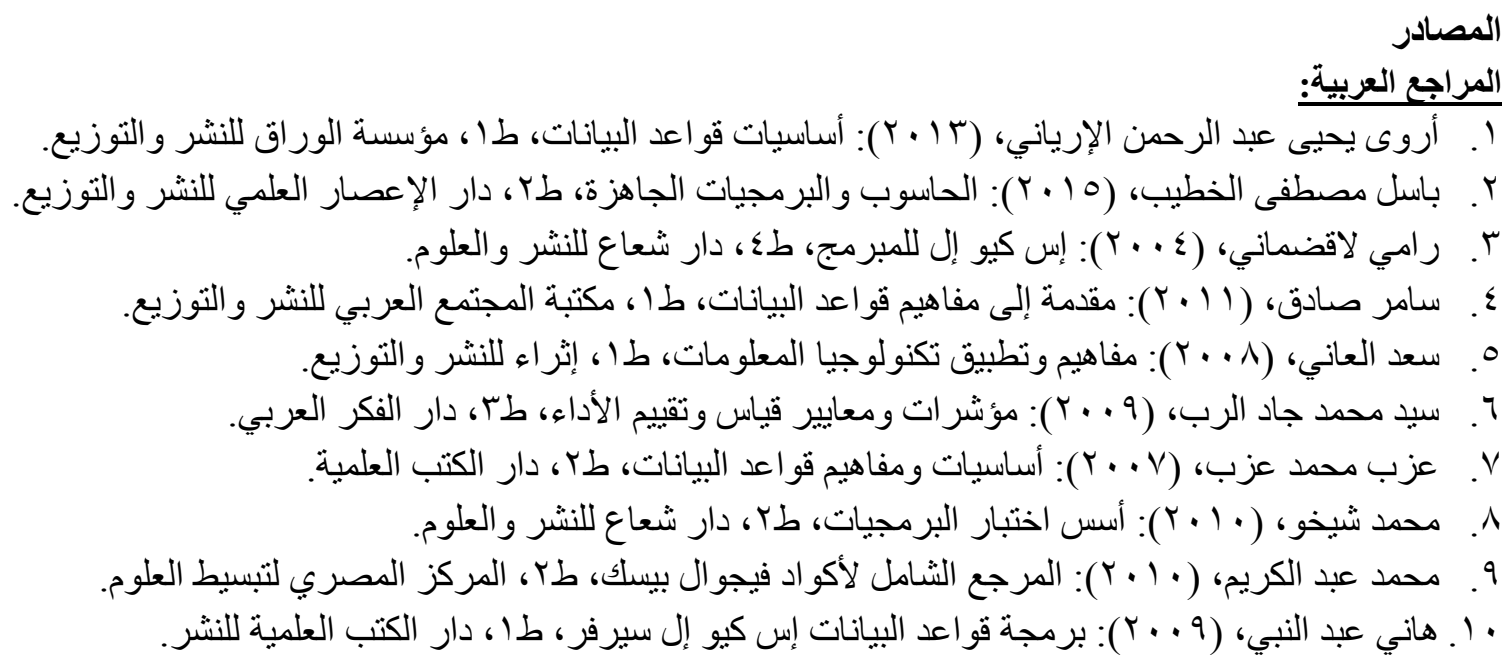

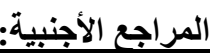

11. Alex Kriegel, (2011): Discovering $\quad$ SQL, e.book from http://www.wrox.com/WileyCDA/

12. Bryan Newsome, (2015): Beginning Visual Basic 2015, e.book from http:/www.wrox.com/WileyCDA/ 
13. Paul Turley, (2017): Professional Microsoft SQL Server 2016 Reporting Services, e.book from http:/www.wrox.com/WileyCDA/

14. Robert Vieira, (2013): Beginning Microsoft SQL Server 2012 Programming, e.book from http://www.wrox.com/WileyCDA/ 
الملحق (إستمارة الاستبيان)

\begin{tabular}{|c|c|c|c|c|c|}
\hline $\begin{array}{r}\text { أواف } \\
\text { ق }\end{array}$ & 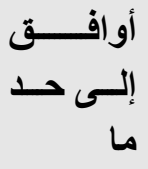 & 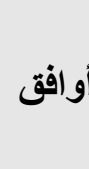 & بشدة أوافـق & 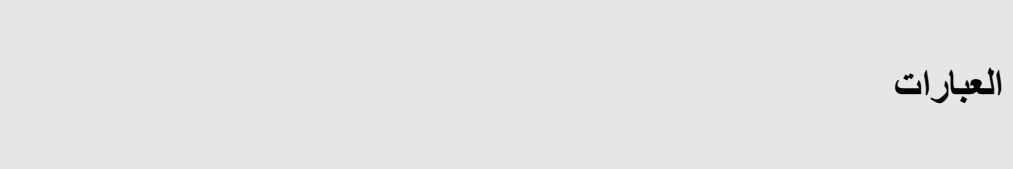 & p \\
\hline & & & & مدى مساهمة البرنامج في تحسين سر عة الأداء بقاعدة بيانات الدر اسات العليا: & أ- \\
\hline & & & & يعمل البرنامج على تسجيل البيانات بسر عة. & 1 \\
\hline & & & & يجري البرنامج عمليات البحث عن البيانات بسر عة. & r \\
\hline & & & & يجري البرنامج عمليات الفلترة على البيانات بسر عة. & r \\
\hline & & & & تساعد خاصية الإكمال التلقائي للقو ائم المنسدلة على تحديد الاختيار بسر عة. & $\varepsilon$ \\
\hline & & & & يصل البرنامج لصلاحيات المستخدمين بسر عة عند الدخول للبرنامج. & ○ \\
\hline & & & & يتسم البرنامج بالاستجابة لأوامر المستخدم بسر عة. & 7 \\
\hline & & & & يستدعي البرنامج التقارير التلخيصية بسرعة. & $\mathrm{V}$ \\
\hline & & & & يتم عمل النسخ الإحتياطي الدوري للبيانات بسر عة. & $\wedge$ \\
\hline & & & & يتم الاستعلام عن المو اد الدراسية التي قام الطالب بتسجيلها بسر عة. & 9 \\
\hline & & & & يتم الاستعلام عن مديونية الطالب بسرعة. & 1. \\
\hline & & & & مدى مساهمة البرنامج في تحسين دقة الأداء بقاعدة بيانات الدر اسات العليا: & بـ \\
\hline & & & & يعمل البرنامج على تنقيح البيانات قبل تخزينها. & 11 \\
\hline & & & & يتم تدقيق البيانات المدخلة عن طريق الاختيار من القو ائم المنسدلة. & it \\
\hline & & & & يقوم البرنامج بتمييز الطالب بدقة عن طريق الرقم الكودي المميز. & it \\
\hline & & & & يقوم البرنامج بتمييز المقرر الدر اسي بدقة عن طريق الرقم الكودي المميز. & $1 \varepsilon$ \\
\hline & & & & يحدد البرنامج مهام كل مستخدم بدقة عند تسجيل دخوله للبرنامج. & 10 \\
\hline & & & & يقوم البرنامج باحتساب مديونية الطلاب المالية بدقة. & 17 \\
\hline & & & & يقوم البرنامج بعرض التقارير التلخيصية المطلوبة بدقة. & iv \\
\hline & & & & تجرى عمليات النسخ الاحتياطي الدوري للبيانات بدقة. & 11 \\
\hline & & & & يتم تكويد الطلاب الجدد بشكل تسلسلي فريد بدقة. & 19 \\
\hline & & & & يسترجع البرنامج المعلومات وفق المعايير التي حددها المستخدم بدقة. & r. \\
\hline & & & & مدى مساهمة البرنامج في تجنب ومنع الأخطاء بقاعدة بيانات الدر اسات العليا: & 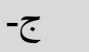 \\
\hline & & & & يمنع البرنامج تسجيل البيانات بشكل خاطئ. & r) \\
\hline & & & & يعطي البرنامج رسائل توجيهية للمستخدم تساعده على الإدخال بشكل صحيح. & Yr \\
\hline
\end{tabular}




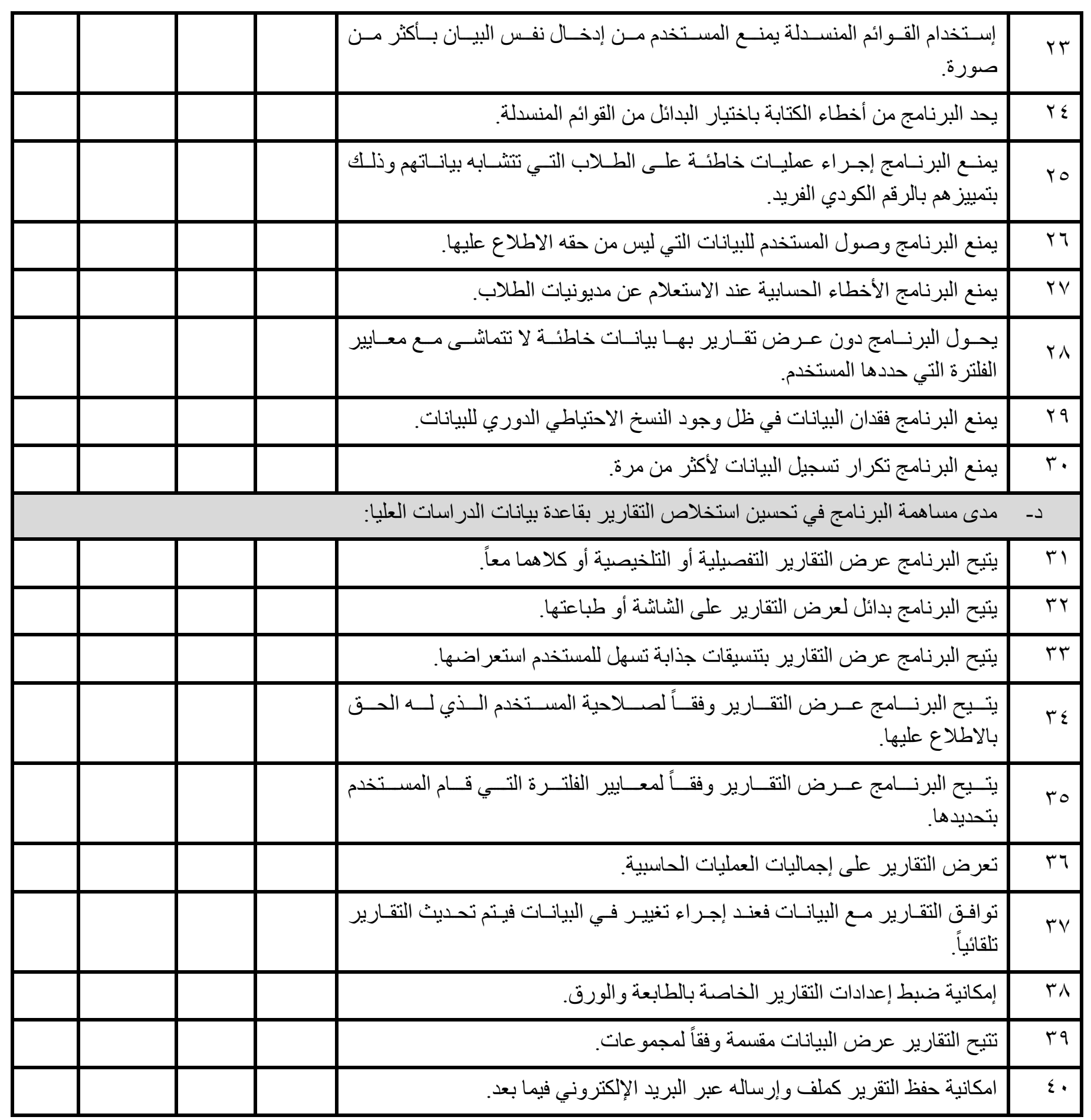

